\title{
1 Esterification of Levulinic Acid with Butanol over ion exchange resins.
}

2 M.A. Tejero, E. Ramírez, C. Fité, J. Tejero ${ }^{(*)}$, F. Cunill

3 Chemical Engineering Department, Faculty of Chemistry, University of Barcelona, Spain.

4 Corresponding author: J. Tejero. Email: jtejero@ub.edu; phone: +34 93402 1308; Fax: +34 934021291

5

\section{Abstract}

7 Alkyl levulinates are biobased chemicals with a great number of applications and great biofuel potential

Keywords: butyl levulinate, levulinic acid, catalysis, ion-exchange resins

\section{Introduction}

In the search for alternative and renewable energy sources, attention has gravitated towards biofuels. Despite the interest, biofuels in their current form present a number of issues. First Generation Biofuels 
(FGB) are produced from classic food crops with well-known technologies. FGB are unsustainable in the long term because of the stress their generalized production would place on food commodities [1]. Second Generation Biofuels (SGB) are derived from non-food crops, preferably from lignocellulosic feedstocks from agricultural wastes. Yet there are obstacles to commercial scale production of SGB, most prominently that the hydrolysis process for the release of sugars from their lignocellulose matrix economically and in high yields still contributes to more than $45 \%$ of biofuel cost production [2].

The transformation of lignocellulosic biomass can yield a number of valuable products that can be used by the chemical industry as platform chemicals. Available techniques to transform lignocellulose into sugars are gasification, pyrolysis and hydrolysis. Hydrolysis requires the lignocellulose to be broken into its constituent parts: cellulose (40-50\%), hemicellulose (25-35\%) and lignin (15-20\%). The hydrolysis of cellulose and hemicellulose catalyzed by $\mathrm{H}_{2} \mathrm{SO}_{4}$ gives place to $\mathrm{C}_{5}$ and $\mathrm{C}_{6}$ sugar monomers such as xylose, glucose, and fructose, and it is today the most important route for obtaining monosaccharides [1]. Fast pyrolysis is also a promising technology. It allows the transformation of the cellulosic fraction of biomass into anhydrosugars (levoglucosan, cellobiosan) which can be hydrolyzed to glucose [3-5]. Levulinic acid (LA) is amongst the platform chemicals obtained from the chemical transformation of lignocellulose-derived sugars, and was highlighted by the United States Department of Energy as a promising building block for chemistry in 2004 and 2010. It can be considered one of the most important platform chemicals derived from biomass because of its reactive nature and the fact that it can be produced at low cost by the Biofine process since 1996 [6,7]: currently 5-8 \$/kg, but prices can be expected to drop to $1 \$ / \mathrm{kg}$ once relevant conversion technologies have been successfully commercialized [8]. As a versatile building block, LA and its derivates have a wide number of applications [9-12].

Alkyl esters of levulinic acid are the most notable of LA derivates with a good number of commercial uses [13-16], including their potential application as green solvents [10]. They have the potential to substitute compounds currently derived from petro-chemical routes for blending to conventional diesel or gasoline because of their low toxicity and physicochemical properties; exhibiting characteristics that make them appropriate for use as cold-flow improvers in biodiesel or oxygenate additives for gasoline and diesel fuel, given that oxygenates and fuel blends must comply with the increasingly stringent 
Levulinate esters can be obtained by direct esterification of levulinic acid with alcohols, typically acid catalyzed (Scheme 1). Sah [17], and later Schuette [18] and Cox [19] were the first to synthesize alkyl levulinates by direct reaction between the acid and the alcohol; publishing the formation of a number of alkyl levulinates in excess of the corresponding alcohol in the presence of $\mathrm{HCl}$. These early studies employed mostly homogeneous catalysis, and reported yields were low (35-75\%). Heterogeneously catalyzed esterification of LA has been attempted more recently, using most often solid Brønsted acids. It has been proposed that the mechanism for the esterification of LA on acidic surfaces involves the adsorption through the protonated carbonyl group (carboxyl group) enabling a nucleophilic attack of the alcohol assisted by an oxygen atom from the catalyst structure [20,21].

\section{SCHEME 1}

The most widely studied alkyl levulinate is ethyl levulinate (EL), both its synthesis pathways and possible applications have been explored thoroughly. Traditionally EL was synthesized by using homogeneous catalysts such as $\mathrm{HCl}, \mathrm{H}_{3} \mathrm{PO}_{4}$ and $\mathrm{H}_{2} \mathrm{SO}_{4}$. Very recently, this reaction has been reexamined extensively with more robust and industrially benign greener catalysts. For this purpose solid acid catalysts have been tested, including supported heteropoly acids [20-23], zeolites [21,24], hybrid catalysts [25-27], sulfated carbon nanotubes [28], Starbon® mesoporous materials functionalized with sulfonated groups [29], sulfated metal oxides [26] and silicas [30,31], and immobilized lipases [32]. It has also been synthesized using commercial acidic sulfonic polystyrene-codivinylbenzene (PS-DVB) resins as reference catalysts, usually Amberlyst 15 and Amberlyst 70 [1,21, 22,28,30]. At the same time, there have been studies aimed at improving the conversion of lignocellulose, glucose or fructose directly into ethyl levulinate in a one-step process catalyzed by either $\mathrm{H}_{2} \mathrm{SO}_{4}$ or $\mathrm{ZrO}_{2}$-based sulfonated catalysts [33-36].

Comparatively, the potential of butyl levulinate (BL) has been left untapped. EL has been considered often in recent years, and was investigated as a novel, bio-based cold flow improver for use in biodiesel fuels [37-38]. As an additive for diesel, BL is even more promising than EL [39]. Both reduce vapor pressure in diesel blends [37], have a freezing point below $-60^{\circ} \mathrm{C}$, their boiling point and flash point are in the acceptable range for diesel fuel, improve lubricity, conductivity and reduce particulate emissions in 
diesel blending. On the other hand, BL is only sparingly soluble in water (up to $1.3 \mathrm{wt} . \%$ ) unlike EL (up to $15.6 \mathrm{wt} . \%)$. Although they both exhibit less energy per volume unit than conventional diesel fuel by $31 \%$ (EL) and 25\% (BL), respectively, this is already an improvement on bioethanol blends. In diesel blends containing $20 \%(\mathrm{v} / \mathrm{v})$ levulinate, EL tends to form a separate liquid phase in most diesel fuels at temperatures significantly above the cloud point of diesel fuel, while BL remains completely soluble in diesel down to the diesel cloud point (around $-25.8^{\circ} \mathrm{C}$ ). Nonetheless, both esters exhibit a very low cetane number, which means blending with these components requires cetane-enhancing additives.

Literature on BL synthesis is sparse: first attempts at synthesis were undertaken with homogeneous catalysts [17-19], and a kinetic model for the esterification of LA with butanol (BuOH) was proposed by Bart et al. [37]. Some work has been made in BL production directly from cellulose with homogeneous catalysis [41]. Esterification of LA with butanol over several types of solid catalysts such as zeolites [42,43], Zr-containing MOFs [44], and heteropolyacid (HPA) supported on acid-treated clay montmorillonite (K10) [45] has been described in literature since then. There have also been sporadic but successful attempts at production and kinetic modelling of BL by esterification of LA via immobilized lipase catalysis [46]. Surprisingly the catalysis with acidic ion-exchange resins has never been studied before.

To the best of our knowledge the synthesis of butyl levulinate by esterification of levulinic acid with 1butanol is not reported over acidic ion-exchange resin, a widely available and inexpensive catalyst, in the open literature. Therefore, the present paper is devoted to the study of the liquid phase synthesis of BL from LA and $\mathrm{BuOH}$ over sulphonated PS-DVB resins. A catalyst screening is carried out in order to select suitable catalysts for obtaining BL. Moreover, it is also desired to elucidate the effect of the resins morphology on their catalytic activity.

\section{Experimental}

\section{2.1. Chemicals}

105 Levulinic acid ( $\geq 98 \%$, Acros Organics) and 1-butanol ( $\geq 99,5 \%$, Acros Organics) were used as reactants.

106 Distilled water, butyl levulinate ( $\geq 98 \%$; Sigma Aldrich) and dibutyl ether ( $\geq 99 \%$, Acros Organics) were 107 used for analysis purposes. 
109 Tested catalysts were acidic PS-DVB ion exchange resins supplied by Rohm and Haas (Amberlyst 15 110 [A15], Amberlyst 16 [A16], Amberlyst 35 [A35], Amberlyst 36 [A36], Amberlyst 39 [A39], Amberlyst 11146 [A46] and Amberlyst 70 [A70]), Purolite (Purolite® CT224 [CT224]) and Aldrich (Dowex 50Wx2

112 [DOW2], Dowex 50Wx4 [DOW4] and Dowex 50Wx8 [DOW8], supplied as beads of 50-100 mesh).

113 A wide set of acidic PS-DVB resins with different morphological properties was used in this study.

114 These include both macroreticular (macroporous) and gel-type (microporous) resins. They also covers a 115 wide range of acid capacities, with monosulfonated or conventionally sulfonated resins (which have a 116 concentration of about one sulfonic group per styrene ring, statistically in para-substitution $[47,48]$ ), 117 oversulfonated (in which the concentration of sulfonic groups has been increased beyond the usual limit 118 of one group per styrene ring [49], where the additional sulfonic groups are predominantly distributed 119 close to the particle surface [50]) and surface sulfonated ones (sulfonated exclusively at the polymer 120 particle surface). Amberlyst 70 should be highlighted, because it has chlorine atoms in its structure, 121 which confer this catalyst a higher thermal stability (yet its acid capacity is only less than $3 \mathrm{mmol} \mathrm{H}^{+} / \mathrm{g}$ ). 122 Resin properties and their acronyms can be seen in Table 1.

\section{TABLE 1}

\subsection{Apparatus and analysis}

125 Experiments were carried out in a $100 \mathrm{~mL}$ stainless steel autoclave operated in batch mode with an 126 electrical furnace controlling temperature. One of the outlets of the reactor was connected directly to a

127 liquid sampling valve, which injected $0.2 \mu \mathrm{L}$ of pressurized liquid into a gas-liquid chromatograph

128 (GLC). The liquid composition was analyzed hourly by using a split mode operation in a HP6890A GLC apparatus equipped with a TCD detector. A $50 \mathrm{~m} \times 0.2 \mathrm{~mm} \times 0.5 \mu \mathrm{m}$ methyl silicone capillary column was

130 used to separate and determine reactants and products. The column was temperature programmed to start 131 at $500 \mathrm{C}$ with a $10^{\circ} \mathrm{C} / \mathrm{min}$ ramp until $250^{\circ} \mathrm{C}$ and held for $6 \mathrm{~min}$. Helium $(\geq 99.998 \%$, Linde) was used as

132 the carrier gas with a total flow rate of $30 \mathrm{~mL} / \mathrm{min}$. All the species were identified by a second GLC

133 (Agilent 6890) equipped with a MS detector (Agilent GC/MS 5973) and chemical database software. A

134 typical chromatogram of the reaction mixture is shown in Figure S1 (supplementary material). 
136 Acid resins were dried at $110^{\circ} \mathrm{C}$ for $2 \mathrm{~h}$ at atmospheric pressure and subsequently at $110^{\circ} \mathrm{C}$ under vacuum 137 overnight (10 mbar). Residual water content was $<3 \%$, as determined by the Fischer method with a Karl 138 Fischer titrator (Orion AF8).

139 The reactor was loaded with $70 \mathrm{~mL}$ of $\mathrm{LA} / \mathrm{BuOH}$ mixture (1/3 molar ratio), heated up to the desired 140 temperature and stirred at $500 \mathrm{rpm}$. Pressure was set at $2.5 \mathrm{MPa}$ with $\mathrm{N}_{2}$ in order to maintain the liquid 141 phase in the reactor and also have the pressure needed to shift liquid samples to the GLC apparatus.

142 When the mixture reached the operating temperature, $0.5 \mathrm{~g}$ of dry catalyst were injected into the reactor 143 from an external cylinder by shifting with $\mathrm{N}_{2}$. Catalyst injection was taken as time zero.

144 Experiments of $8 \mathrm{~h}$ duration were carried out at $80^{\circ} \mathrm{C}$. Initial excess of alcohol was selected to shift 145 the equilibrium to the production of the ester. However, the closer to the stoichiometric ratio is the 146 initial mixture, the higher the amount of ester obtained at equilibrium. Experimentally we found that 147 a mixture $\mathrm{AL} / \mathrm{BuOH}$ with initial molar ratio lower than $1 / 3$ split into two phases due to the formation 148 of water over the reaction. Therefore, we use an initial molar ratio $\mathrm{AL} / \mathrm{BuOH}$ of $1 / 3$ in all the 149 experiments. To work with such alcohol excess have the advantages of minimizing the possible 150 formation of humins by polymerization of LA and, since the alcohol excess was smaller than 1/10, 151 to minimize the formation of dibutyl ether by intermolecular dehydration of 1-butanol too [30].

152 The use of such small catalyst mass ( $0.5 \mathrm{~g}$ of dry catalyst; catalyst loading < $1 \%)$ allows us to work free of spurious effects on the reaction rate as can be seen in the dehydration reactions to ether of 1-butanol

154 [53] or 1-hexanol [54] on Amberlyst 70, or 1-pentanol over CT224 and Dowex 50Wx4 [51] carried out 155 in similar setups.

156 Evaluation of the possible effects of the stirring speed on external mass transfer was not within the 157 bounds of this study. However, the assumption that external mass transfer does not limit reaction rates at $158500 \mathrm{rpm}$ stirring speed was made, based on previous studies on other reaction systems under similar reaction conditions performed at the same temperature range, e.g. the esterification of lactic acid with

160 methanol [55] or that of acrylic acid with 2-ethyl hexanol [56] over Amberlyst 15. In addition, the 161 dehydration reactions to ether of 1-butanol [53] or 1-hexanol [54] on Amberlyst 70, or 1-pentanol over 
$162 \mathrm{CT} 224$ and Dowex $50 \mathrm{Wx} 4[51]$ at temperatures as high as $150^{\circ} \mathrm{C}$ also shows that external mass transfer

163 influence at such stirring speed is negligible.

164 Macroreticular resins were used with only a fraction of the commercial distribution of particle sizes $(0.4<$ $\left.165 \mathrm{~d}_{\text {bead }}<0.6 \mathrm{~mm}\right)$, and gel-type resins with the commercial distribution of particle sizes $\left(0.15<\mathrm{d}_{\text {bead }}<0.3\right.$ $166 \mathrm{~mm}$ for Dowex catalysts, and $\mathrm{d}_{\text {bead }} \approx 0.32 \mathrm{~mm}$ for CT224 [57]). A large amount of experimental work at 167 about $80^{\circ} \mathrm{C}$ on esterification reactions is found in the open literature involving compounds of similar 168 molecular size to LA, $\mathrm{BuOH}$ and $\mathrm{BL}$. Among them, there may be mentioned the reaction of acrylic acid 169 with 2-ethyl hexanol over Amberlyst 15 [56], and with 1-butanol over Amberlyst 35 [58] and Amberlyst 17015 [59], the esterification reaction of lactic acid with methanol over Amberlyst 15 [55], that of propionic 171 acid with 1-butanol over Amberlyst 35 [60], that of acetic acid with 1-pentanol over Dowex $50 \mathrm{Wx} 8$ [61], 172 or that of succinic acid with ethanol over Amberlyst 70 [62]. As these works show, in swollen state the 173 influence of the diffusion on reaction rate is negligible when macromolecular and gel-type resin beads of 174 similar size to those of the present study are used.

175 In each experiment, LA conversion $\left(\mathrm{X}_{\mathrm{LA}}\right)$ and selectivity to $\mathrm{BL}\left(\mathrm{S}_{\mathrm{BuOH}}^{\mathrm{BL}}\right)$ were estimated by Eqs, (1) and 176 (2), respectively.

$177 \quad X_{L A}=\frac{\text { mole of } \text { LA reacted }}{\text { mole of LA initially }} \times 100[\%, \mathrm{~mol} / \mathrm{mol}]$

$S_{B u O H}^{B L}=\frac{\text { mole of } L \text { A reacted to form } B L}{\text { mole of } L A \text { reacted }} \times 100[\%, \mathrm{~mol} / \mathrm{mol}]$

179 Reaction rates of BL formation at any time were estimated from the functions of variation of $\mathrm{n}_{\mathrm{BL}}$

180 (number of produced BL mole) versus time, where $\mathrm{w}$ is the mass of dry catalyst

$181 \quad r_{B L}=\frac{1}{w}\left(\frac{d n_{B L}}{d t}\right)_{t}\left[\frac{\mathrm{mol} \mathrm{BL}}{\mathrm{kg} \cdot \mathrm{h}}\right]$

182 Finally, the turnover frequency of BL formation was estimated by dividing the reaction rate by the 183 number of acid sites per gram of dry resin (acid capacity), $\left[\mathrm{H}^{+}\right]$.

$184 T O F_{B L}=\frac{r_{B L}}{\left[H^{+}\right]}\left[\frac{\mathrm{mol} \mathrm{BL}}{e q H^{+} \cdot h}\right]$ 
185 A single experiment (Dowex 50Wx2) was replicated twice with perfect experimental overlap. Therefore,

186 it was concluded that the experiments are fully replicable and experimental error was less than 3-5\%.

\section{3. Results and discussion}

\subsection{Morphology of the swollen resins}

190 Ion exchange resins are nearly spherical beads of sulfonated PS-DVB copolymers. Copolymerization of

191 styrene and DVB gives place to an ensemble of entangled styrene-DVB chains with no spaces among

192 them in dry state (gel-type resins). However, if copolymerization proceeds in the presence of a solvent

193 such as toluene (soluble in styrene-DVB mixtures but unable to react with both co-monomers), it is

194 excluded from the polymer and the spaces filled by the solvent become pores (macroreticular resins).

195 These resins consist of large agglomerates of gel-phase micro-spheres; each one showing smaller nodules

196 that are more or less fused together [47]. In between the nodules there is a family of very small pores

197 (micropores), and in between the micro-spheres a second family of intermediate pores of diameter 8-20

$198 \mathrm{~nm}$ (mesopores) is observed. A third family of large pores of diameter 30-80 $\mathrm{nm}$ (macropores) is located

199 between the agglomerates. Macropores, unlike meso- and micropores, are permanent and can be detected

200 by standard techniques of pore analysis, i.e. adsorption-desorption of $\mathrm{N}_{2}$ at $77 \mathrm{~K}$. On the contrary, meso-

201 and micropores appear in polar media able to swell the polymer and can be detected in aqueous media by

202 characterization techniques such as inverse steric exclusion chromatography (ISEC) [64]. Morphological

203 data of tested resins in dry state can be found in Table S1 (Supplementary Material).

204 Acidic ion-exchange resins experience swelling when they are in a polar medium and, as a result,

205 morphology changes occur leading to the emergence of non-permanent spaces in the gel-phase of both macroreticular and gel-type resins. The inherent stiffness or flexibility of the resin structure is largely determined by their divinylbenzene content (DVB \%) or crosslinking degree. In the styrene-DVB

208 copolymerization process, DVB units links the styrene chains thereby crosslinking the polymer. Resins

209 with low DVB \% are thus less cross-linked, and as a consequence have a more flexible morphology.

210 Usually, resins with a low degree of cross-linking suffer the effects of swelling in a more pronounced

211 manner. It can be seen at a glance that resins highly swell in our reaction system, firstly in contact with 
212 reactants (butanol and levulinic acid), and later by interaction with reaction products, especially water. It

213 is therefore appropriate to characterize the morphology of tested resins in swollen state.

214 Analysis of ISEC data provides a useful characterization of swollen resins. The usual approach is based 215 on modelling of the porous structure as a set of discrete fractions, each composed of pores having simple 216 geometry and uniform sizes. In macroreticular resins a part of the new spaces generated on swelling can 217 be characterized by the cylindrical pore model by estimating the surface area, $S_{\text {pore }}$, pore volume, $V_{\text {pore }}$, 218 and mean pore diameter, $\mathrm{d}_{\text {pore }}$. These spaces are in the range of mesopores and are placed between gel219 phase aggregates. Table 2 shows $S_{\text {pore }}, V_{\text {pore }}$ and $d_{\text {pore }}$ of macroporous resins tested. In gel-type resins no spaces were detected in the mesopore range.

\section{TABLE 2}

222

However, the cylindrical pore model is not applicable to describe spaces between polymer chains formed as a result of gel-phase polymer swelling. The model developed by Ogston can more accurately describe the three-dimensional network of swollen polymer in which gel-phase spaces (micropores) are described by spaces between randomly oriented rigid rods [64]. The characteristic parameter of this model is the specific volume of the swollen polymer (volume of the free space plus that occupied by the skeleton), $\mathrm{V}_{\text {sp. }}$. The Ogston model also distinguishes between zones of swollen gel phase of different density or polymer chain concentration (total rod length per volume unit of swollen polymer, $\mathrm{nm}^{-2}$ ) [65-67].

However, swelling does not occur in a uniform manner in a resin bead. Gel-phase porosity is described as zones of different chain density [66]. Chain density zones have been related to spaces of equivalent pore diameter $\left(d_{\text {pore,eq }}\right)$ by the Ogston Model [51]: $0.1 \mathrm{~nm} / \mathrm{nm}^{3}\left(d_{\text {pore,eq }}=9.3 \mathrm{~nm}\right), 0.2 \mathrm{~nm} / \mathrm{nm}^{3}\left(d_{\text {pore,eq }}=4.8\right.$ $\mathrm{nm}), 0.4 \mathrm{~nm} / \mathrm{nm}^{3}\left(\mathrm{~d}_{\text {pore }, \mathrm{eq}}=2.6 \mathrm{~nm}\right), 0.8 \mathrm{~nm} / \mathrm{nm}^{3}\left(\mathrm{~d}_{\text {pore }, \text { eq }}=1.5 \mathrm{~nm}\right)$ and $1.5 \mathrm{~nm} / \mathrm{nm}^{3}\left(\mathrm{~d}_{\text {pore,eq }}=1 \mathrm{~nm}\right)$. Distribution of the different polymer density zones of tested resins swollen in water is shown in Fig. 1. As seen, when the DVB content is high the overall polymer density is accordingly high, with small $\mathrm{V}_{\mathrm{sp}}$ values. Gel-type resins CT224, Dowex 50Wx2, Dowex 50Wx4 and Dowex 50x8 and macroreticular resins with low cross-linking degree Amberlyst 70 and Amberlyst 39 show low polymer densities $(0.2-$ $0.8 \mathrm{~nm}^{-2}$ ) typical of an expanded polymer whereas macroreticular resins with medium and high crosslinking degree Amberlyst 36, Amberlyst 16, Amberlyst 35, Amberlyst 15 and Amberlyst 46 present high 
chain concentration $\left(0.8-1.5 \mathrm{~nm}^{-2}\right)$ characteristic of a very dense polymer mass. Noticeably, Dowex

$24050 \mathrm{Wx} 8$ shows zones with high polymer density $\left(1.5 \mathrm{~nm}^{-2}\right)$, probably due to its crosslinking degree (8\%)

241 which confers high stiffness to del-type resins. It is usually expected that lower polymeric density zones

242 present better accessibility than more densely packaged ones. The pore size distribution of the swollen

243 gel phase in water is probably quite representative of the morphology of the catalyst in the reaction

244 medium because the resin swelling in alcohols and water is comparable [57,65].

FIGURE 1

246

247

\subsection{Preliminary experiments}

Firstly, blank experiments without catalyst were performed at $80^{\circ} \mathrm{C}$. Despite the absence of a solid catalyst the reaction occurred to some extent, probably self-catalyzed by LA. After the initial heat-up there was significant conversion of levulinic acid $\left(\mathrm{X}_{\mathrm{LA}} \approx 15 \%\right.$ at $\left.\mathrm{t}=0\right)$, but then the reaction progressed slowly and $\mathrm{X}_{\mathrm{LA}}<25 \%$ were reached at $8 \mathrm{~h}$ of reaction. Aside from $\mathrm{BL}$ and water, only small amounts of dibutyl ether (DBE) were detected from the reaction of excess $\mathrm{BuOH}$.

\subsection{Catalyst screening}

The results of the catalyst screening runs are summarized in Table 3. The conducted experiments show that acidic PS-DVB ion-exchange catalysts highly accelerates the reaction rate of esterification of LA, with respect to the homogeneous reaction. LA conversions are between 63.9\% (Amberlyst 46) and 93.6\% (Dowex 50Wx2) at $8 \mathrm{~h}$ reaction. DBE is the only byproduct observed, but it is produced only in small quantities $(<2 \mathrm{wt} . \%)$. It is to be noted that under present operating conditions selectivity to butyl levulinate, $\mathrm{S}_{\mathrm{BuOH}}^{\mathrm{BL}}$, is higher than $99 \%$ over all the resins tested.

\section{TABLE 3; FIGURE 2}

Figure 2 shows, for each catalyst, the evolution of LA conversion with contact time $\left(w \cdot t / \mathrm{n}^{0} \mathrm{LA}\right)$, so that the slope of the curves is a direct measure of the reaction rate in a batch reactor. As seen, in general, gel-type resins provided higher reaction rates than macroreticular ones; the surface sulfonated resin Amberlyst 46 being the least active of all tested resins. It appears that catalysts with greater capacity for swelling favor LA esterification conversions. Acidic ion-exchange resins swell to a higher degree when submerged in 
polar liquid medium. Because of the high polarity of LA and butanol, and the formation of water over the reaction, resins are highly swollen in the reaction medium. Furthermore, gel-type resins have a higher swelling capacity than macroreticular ones because of lower percentage of cross-linking agent (DVB) which confers them less rigid morphology, as shown in Table S2 (Supplementary Material). Thus resins with a lesser cross-linking degree present higher esterification rates and accordingly LA conversions.

The effect of the number of active sites is unclear. On one hand, oversulfonated CT224 is less active than monosulfonated Dowex 50Wx4 (both gel-type and 4\% DVB). This might answer to the fact that resin oversulfonation confers a certain additional stiffness to the polymer morphology, which reduces swelling. On the other hand, macroreticular Amberlyst 15 and Amberlyst 35 have 20\% DVB (high crosslinking degree) and no differences were observed in their catalytic behaviour. In addition, oversulfonated Amberlyst 36 was marginally better than monosulfonated Amberlyst 16 (12\% DVB). In this case, where high amounts of cross-linking agent furnish a very rigid morphology, a higher number of available active sites (surface macropores) can slightly counteract this effect. The lowest activity was that of A46, which is surface-sulfonated and therefore has a low number of active sites. LA conversion is only lower by $9 \%$ than that obtained over Amberlyst 15, Amberlyst 16 and Amberlyst 35. This suggests that for resins with higher cross-linking degree (DVB\% $\geq 12$ ), swelling might be so poor that the reaction takes place mainly on active sites close to the surface. This is consistent with the observation that a good swelling capacity in $\mathrm{BuOH}$ is desirable for a catalyst of the LA esterification reaction. In the case of Dowex 50Wx8 and Amberlyst 39 (8\% DVB) it is observed that the gel-type resin is less active. This fact can be justified in terms of the amount of swollen gel phase: Amberlyst 39 has higher $\mathrm{V}_{\mathrm{sp}}$ values and lower polymer density in the different volume zones in swollen estate than Dowex 50Wx2 as seen in Figure 2.

On a side note, thermostable Amberlyst 70 showed unexpected high activity. As Figure 2 shows, reaction rates are close to that of Dowex 50Wx8; yet lower than those of Amberlyst 39. Amberlyst 70 has a lower number of active sites than Dowex 50Wx8 and Amberlyst 39 (all 8\% DVB; see Table 1). On the other hand, despite Amberlyst 70 has lower $\mathrm{V}_{\mathrm{sp}}$ than the other two resins, its overall polymer density is also lower. Presumably, the best behavior of Amberlyst 70 could be due to the combination of a less stiff inner morphology, and a higher acid strength of acid sites due to the electron donating effect of chloride atoms present in the thermostable resin, which might have a compensatory effect. 
As expected for non-autocatalytic reactions, reaction rates diminish as LA conversion increases. Figure 3

294 shows that Dowex 50Wx2 and Dowex 50Wx4 present the highest initial reaction rates, closely followed by CT224, Amberlyst 39 and Dowex 50Wx8. Therefore, gel type-resins have generally higher reaction rates as previously discussed. In the same way, Amberlyst 46 shows the lowest reaction rates of all catalysts tested. However, as seen in Fig. 4, Amberlyst 46 presents the highest turnover frequency (TOF) estimated as the reaction rate per active site (Eq. 4). This can be safely attributed to the great accessibility of its surface active sites despite their low number, revealing that active site accessibility is an issue. We can assume that the reaction rates achieved in surface sites are similar for all resins tested, and that reaction rates in internal active sites are lower. In this way, TOF values are rather an average of activity of all resin active sites, under the hypothesis that all of them are accessible. Resins with a flexible morphology, favoring swelling would have more accessible sites and higher TOF. Indeed, Amberlyst 46 is the resin presenting a highest TOF because all its active centers are surface-located and therefore easily accessible, although low in number. Dowex 50Wx2, Amberlyst 70 and Dowex 50Wx4 follow most closely Amberlyst 46 in terms of the highest TOF. It is worth noting that Amberlyst 70, similarly to Amberlyst 46, has a low number of active sites. Nonetheless, this is compensated by a very flexible internal morphology, relatively high $\mathrm{V}_{\mathrm{sp}}$ and low chain polymer density in the swollen state (Fig. 1). Despite being a gel-type resin and having a high number of active sites, TOF for Dowex 50Wx8 is low, mostly because unlike Amberlyst 70, polymer chain density in the swollen state is high, rendering many internal sites inaccessible. Macroreticular resins with high amounts of DVB have the lowest TOF, which is attributable to the stiffness of their morphology.

\section{FIGURE 3; FIGURE 4}

\subsection{Influence of the resins properties on their catalytic activity}

This study has attempted to ascertain which catalyst properties have a greater effect on catalyst efficiency

316 for the specific reaction of the esterification of LA with $\mathrm{BuOH}$. Figs. 5A to 5F plot $\mathrm{X}_{\mathrm{LA}}$ as a function of

317 relevant chemical and morphological properties of PS-DVB such as acid capacity, DVB\%, $\mathrm{V}_{\mathrm{sp}}$ and pore

318 surface and volume in the mesopore range in swollen state at different reaction times. 
It was found that although the acid protons are those which allow the catalytic process, there is no clear relationship between $\mathrm{X}_{\mathrm{LA}}$ and the number of active sites (acid capacity) as shown in Fig. 5D. As seen LA conversion increases with acid capacity, but in the range 4.8-5.4 meq $\mathrm{H}^{+} / \mathrm{g}$ many resins with similar acid capacity show very different $\mathrm{X}_{\mathrm{LA}}$ values, what implies that factors as acid strenght or morphological properties might have an important role in the catalytic activity of resins.

Ion exchange resins exhibit high concentrations of acid sites whose nature tends to be highly uniform and with a relatively low acid strength. Acid strength of sulfonic groups is quite similar for ion exchange resins, but some small differences are found depending on their morphology. The ammonia adsorption enthalpy $\left(-\Delta \mathrm{H}_{\mathrm{ads}}\right)$ have been used to quantify the difference in acid strength rather that the acid strength itself. By using the flow ammonia adsorption calorimetry technique $\left(-\Delta \mathrm{H}_{\mathrm{ads}}\right)$ values ranging from $117 \pm 2$ $\mathrm{kJ} / \mathrm{mol}$ (Amberlyst 35, Amberlyst 36 and Amberlyst 70) to $106 \pm 3 \mathrm{~kJ} / \mathrm{mol}$ (Dowex 50Wx2) as shown in Table 4. Acid capacity measured by this technique coincide well with values determined by titration with standard base for macoreticular resins. For gel-type resins there are some problems attributable to the fact that not all acidic sites are accessible in dry state $[48,68]$. However, it can be accepted that acid sites are of Brönsted type. It is also seen that oversulfonated resins have a slightly higher acid strength than monosulfonated ones. However, despite that Amberlyst 35 has higher acid capacity and a bit higher acid strength than Amberlyst 15, reaction rates of BL formation and LA conversions obtained on both resins are very similar. On the contrary, Amberlyst 35 and Amberlyst 36 have very similar acid capacity and acid strength, but reaction rate and LA conversion on Amberlyst 36 are some higher. Since those resins have significantly different morphologies in swollen state, it is assumed that the effect of acid strength is masked by the resin morphology. This would be in agreement with the fact that the monosulfonated resin Dowex 50Wx2, the most active resin, has the lowest acid strength but the higher swelling capacity.

\section{TABLE 4}

343 Morphology is thus the more relevant factor; underlining that accessibility to active sites is crucial to

344 high catalyst activity. In swollen state, only macroreticular resins develop spaces in the macro- and mesopore ranges, which are characterized by pore volume and surface area, and mean pore diameter. Nonetheless, these parameters can clue us in regards to issues of accessibility. It is seen in Fig. 5C that 
resins with larger macropores have slightly larger conversions at $8 \mathrm{~h}$ reaction. This fact cannot be fully

348 explained by accessibility issues because macropores have an average diameter ten times larger than

349 estimated molecules length $\left(\mathrm{d}_{\mathrm{LA}}=6.78 \AA \mathrm{d}_{\mathrm{BL}}=14.3 \AA\right.$ by using ChemBioOffice 2012). A higher total pore

350 volume and surface area of macropores are generally linked to lower $\mathrm{X}_{\mathrm{LA}}$ values (Figs. 5A and 5B), since

351 higher pore surfaces and volumes correspond with highly cross-linked and stiff resins.

352 More relevant to catalyst efficiency than catalyst macropore size is accessibility of reactants molecules to 353 acid centers, which is facilitated by the polymer swelling. Polar molecules show an affinity for sulfonic

354 groups and their network of hydrogen bonds. When immersed in a polar media polymeric catalysts swell

355 because of the interaction of the medium with the catalyst structure (sulfonic groups and polymer

356 chains). In the swollen state a number of new spaces equivalent to mesopores (9.3-4.8 nm) and

357 micropores (2.6-1 nm) appear [51], resulting in an additional number of accessible sites to be added to

358 the surface ones. The amount of DVB (cross-linking agent) used in resin synthesis determines the

359 formation of macropores (permanent pores), but both in macroreticular resins and in gel-type ones new

360 pores appear by the swelling of the polymer in suitable media. A more rigid structure with higher cross-

361 linking degree hinders polymer swelling by locking polymer chains together and limiting their ability to

362 uncoil, rendering them less flexible. As seen in Fig. 5E, $\mathrm{X}_{\mathrm{LA}}$ decreases almost linearly on increasing

363 DVB\%. Likewise, at the same value of DVB\% several data points with slightly different conversions

364 appear which are due to differences in acid capacity.

365 As a whole, higher reaction rates roughly correspond to high $\mathrm{V}_{\mathrm{sp}}$ values (Fig. 5F). This trend is well-

366 defined and consistent with previous observations. $\mathrm{V}_{\mathrm{sp}}$ gives an accurate idea of the magnitude of

367 polymer swelling in polar medium. Nonetheless, the matter is more complex. Polymeric resins do not

368 swell uniformly when immersed in any liquid medium. When modeling the swollen gel phase, it is

369 depicted as a set of discrete fractions in which gel-phase porosity is described as zones of different chain

370 density. For each tested catalyst, Figure 6 plot $\mathrm{X}_{\mathrm{LA}}$ at 2, 4 and $8 \mathrm{~h}$ (right axis), and the volume of each

371 zone of different polymer density as well as $\mathrm{V}_{\mathrm{sp}}$ (left axis). It is seen that the density of each volume

372 fraction has as much influence on catalyst activity as the total value of $\mathrm{V}_{\mathrm{sp}}$. In almost all catalysts which

373 provided high $\mathrm{X}_{\mathrm{LA}}$ values, large medium to low chain density fractions were reported $\left(0.1-0.4 \mathrm{~nm} / \mathrm{nm}^{3}\right)$. 
374 Thus, the more densely packed polymeric structures in the swollen state are found to be disadvantageous 375 to have higher reaction rates, and consequently higher LA conversions.

\section{FIGURE 6}

377 Fig. 6 can also shed light as to why the conventionally sulfonated Amberlyst 39 (macroporous) and

378 Dowex 50Wx8 (gel-type) have noticeably different catalytic activity despite having the same \%DVB and 379 acid capacity, what seems to contradict the general trend for gel-type resins to give higher $\mathrm{X}_{\mathrm{LA}}$ values. It 380 is seen that Dowex 50Wx8 has not only lower $\mathrm{V}_{\mathrm{sp}}$, but contains mostly densely packed polymer zones. It 381 can also back up our explanation about why CT224 is disadvantageous with regards to Dowex 50Wx4:

382 CT224 does have denser structure as well as a lower $\mathrm{V}_{\mathrm{sp}}$. It is also seen that Amberlyst 70 morphology in 383 the swollen state fall entirely in the aforementioned range of low chain density fractions in which higher conversions are reported. Thus the fact that LA conversion on Amberlyst 70 is reported to be relatively high regardless of its lower acid capacity can be chalked up not only to the slightly higher acid strength of its active sites but to the resulting lighter density of its swollen morphology.

From Figs. 5 and 6 it is clear that the ability of swelling is a key for catalyzing LA esterification to BL. Resins, on swelling not only changes their morphology but also changes the density of acid sites. Fig. 7 shows the effect of the parameter $\left[\mathrm{H}^{+}\right] / \mathrm{V}_{\mathrm{sp}}$ on the activity of tested catalysts. The parameter $\left[\mathrm{H}^{+}\right] / \mathrm{V}_{\mathrm{sp}}$ is a rough measure of the density of acid sites in the swollen polymer. As can be seen, LA conversion at $8 \mathrm{~h}$ decreases on increasing acid site density, so that the smaller the acid density of resins, the higher their catalytic activity. The best catalysts (Dowex 50Wx2, Dowex 50Wx4 and Purolite CT224) are also those with lower $\left[\mathrm{H}^{+}\right] / \mathrm{V}_{\mathrm{sp}}$ values. It is also seen that resins with $\left[\mathrm{H}^{+}\right] / \mathrm{V}_{\mathrm{sp}}<5$ show the lowest activity, and this is almost independent of the acid density. Amberlyst 46 and Amberlyst 70 are clearly out of the general trend, which can be explained by their particular morphology (Amberlyst 46 is surface sulfonated) and composition (Amberlyst 70 has chlorine atoms in its polymeric estructure), and the lower acid capacity compared to the other resins. We can conclude that best catalysts for this reaction are those with good swelling capacity and low acid site density in swollen state. 
402 The use of ion exchange resins to catalyze the esterification of $\mathrm{LA}$ with $\mathrm{BuOH}$ is a good option from the

403 viewpoint of green synthesis, particularly the low cross-linked gel-type resins Dowex 50Wx2, Dowex

$40450 \mathrm{Wx} 4$ and Purolite CT224. Regarding the use of $\mathrm{H}_{2} \mathrm{SO}_{4}$ [40], in addition to avoiding the risk to blacken

405 the reaction product by the action of that acid, ion exchange resins have the advantages of heterogeneous

406 catalysis: easy separation of catalysts from liquid medium, and minimizing reactor corrosion by acid. In

407 comparison with zeolites [42-44] and montmorillonite-supported heteropolyacids (HPA) [45], gel-type

408 resins with 2-4\% DVB (especially Dowex 50Wx2) are not only very selective, are also more active

409 (Table 5). These resins give good reaction rates at $80^{\circ} \mathrm{C}$ whereas the best results of Maheria et al. [42],

410 Nandiwale and Bokade [43], Cirujano et al. [44] and Dharne and Bokade [45] has been obtained at

$411120^{\circ} \mathrm{C}$. As seen in Table 5 , it is to be noted that Dowex 50Wx2 provides a $\mathrm{X}_{\mathrm{LA}} \approx 95 \%$ at much shorter

412 contact times than zeolites or montmorillonite supported HPA [42,43,45], what implies the volume of an

413 industrial reactor would be much lower, and also it works a lower temperature. For a possible industrial

414 application, low temperature operation implies energy savings of great importance both environmentally

415 and economically. Moreover, ion-exchange resins are effective at initial LA/BuOH molar ratios of 1/3

416 leading to high BL production, a green chemistry important point because the environmental relevance of

417 working with little excess of reactant. As for immobilized lipase catalysts, despite being attractive since

418 they are active and selective below $60^{\circ} \mathrm{C}$, their use has the drawbacks that a solvent is necessary (contrary

419 to the precepts of green chemistry) and the loss of activity in each successive reuse as reported by Yadav

420 and Borkar [46]. On the contrary, resins are usually stable below the maximum operating temperature.

\section{TABLE 5}

422 On the selection of a suitable catalyst for the LA esterification, it is necessary that retain its activity for a long time. Ion exchangers deactivate due to hydrolysis of sulfonic groups and/or blocking of the active sites because of the formation of substances by polymerization or polycondensation of reactants, reaction products and/or compounds originated by reaction between reactants or reaction products. Thermal degradation of the resins occurs due to desulfonation by hydrolysis, and it takes place significantly in aqueous media above $180^{\circ} \mathrm{C}$ on macroreticular polymers, resulting in a substantial degradation of their 
morphology $[69,70]$. However, hydrothermal treatments reveal that half-life of gel-type resins, as Dowex $50 \mathrm{Wx} 8$, is higher than $800 \mathrm{~h}$ above $150^{\circ} \mathrm{C}$ [71], and Dowex 50Wx2 and Amberlyst 70 retain acid capacity fully after $24 \mathrm{~h}$ at $150^{\circ} \mathrm{C}$ in a stream of bidistilled water [72]. Likewise, it has been found that there is no loss of acid groups of oversulfonated Amberlyst 35 after hydrothermal treatment of $6 \mathrm{~h}$ [48].

On the other hand, it has been reported that gel-type resins maintain their activity and selectivity in aqueous media for more of $80 \mathrm{~h}$ on stream at $120-150^{\circ} \mathrm{C}$. In particular, in the dehydration reaction between ethanol and 1-octanol to ethyl octyl ether (EOE) in a fix reactor, reaction rates on Dowex $50 \mathrm{Wx} 2$ only dropped by $10 \%$ after $70 \mathrm{~h}$ at $150^{\circ} \mathrm{C}$ [72]. Interestingly, the catalyst recovered its activity after drying in a $\mathrm{N}_{2}$ flux and, in addition, its acid capacity was unchanged. Moreover, in the same setup Amberlyst 70 was found to be reusable in the synthesis of EOE without activity loss after three $50 \mathrm{~h}$ on stream cycles [72]. It should be noted also that some macroporous resins, despite having some desulfonation at $150^{\circ} \mathrm{C}$ may be reused for some cycles. In particular, Amberlyst 15, whose maximum operating temperature is $120^{\circ} \mathrm{C}$, might be reused several times at $150^{\circ} \mathrm{C}$ without activity loss as it was shown in dehydration reaction of 1-butanol to di-n-butyl ether [53]. In this case, morphology changes provides higher surface area, but some desulfonation is detected. The maintaining of catalytic activity for a few runs would be the result of those opposite changes in the resin.

Regarding to esterification reactions, many examples of resins reuse can be found in the open literature at $65-120^{\circ} \mathrm{C}$. For example: the acetylation of glycerol at $105^{\circ} \mathrm{C}$ on Amberlyst 36 and Dowex 50Wx2 [73], Amberlyst 35 [74]; esterification of cooking oil with methanol on Amberlyst 15 at $65^{\circ} \mathrm{C}$ [75] and $90^{\circ} \mathrm{C}$ [76]; the reaction of phthalic acid with methanol at $120^{\circ} \mathrm{C}$ on Amberlyst 36 [77]; or the esterification of acrylic acid with isobutanol at $85^{\circ} \mathrm{C}$ on Amberlyst 131 (a gel-type monosulfonated resin similar to Dowex 50Wx4) [78]. In all cases 4 reuse cycles were reported with the exception of esterification of cooking oil with methanol where Amberlyst 15 was reused 8 times. A common feature of these examples is that the alcohol was initially in excess. It is noteworthy that when polarity of the reaction medium is reduced because the presence of a entrainer the reusability is worst, as it is seen in the acetylation of glycerol in the presence of toluene where selectivity to triacetyl ester diminished after each reuse [79].

454 Since we have conducted our experiments at $80^{\circ} \mathrm{C}$, well below the maximum operating temperature of tested resins, and with alcohol excess, it is assumed that acidic resins would be stable enough for 
potential use in industry, especially resins Dowex 50Wx2, Dowex 50Wx4 and CT224, the most active catalysts found in the present study.

458

459

460

461

462

463

464

465

466

467

468

469

470

471

472

473

474

475

476

477

478

479

480

481

482

\section{Conclusions}

The catalyst screening revealed that BL can be successfully produced in liquid phase from LA and $\mathrm{BuOH}$ over acidic PS-DVB catalysts at $80^{\circ} \mathrm{C}$ at an initial molar ratio $\mathrm{LA} / \mathrm{BuOH}$ of $1 / 3$ and catalyst loading $<1 \%$. The reaction takes place with selectivity to BL higher than $99.5 \%$, and the only side reaction detected is the parallel reaction of etherification of $\mathrm{BuOH}$ to $\mathrm{DBE}$, although $\mathrm{DBE}$ is produced in very small quantities. After $8 \mathrm{~h}$, the use of gel-type resins (e.g. Dowex 50Wx2, Dowex 50Wx4 and CT224) led to high conversions of LA into BL, so that BL yields of 90.5-93.5\% are obtained. It is seen that gel-type PS-DVB resins with a higher amount of swollen polymer phase and low acid site density in the swollen polymer $\left(\left[\mathrm{H}^{+}\right] / \mathrm{V}_{\mathrm{sp}}\right)$ show higher activity. Best results are obtained with the gel-type resin Dowex 50Wx2 (monosulfonated, 2\% DVB).

The synthesis of BL is highly related to morphological resins properties that promote accessibility to acid centers. Consequently, in order to synthesize moderately bulky esters such as BL, a greatly expanded polymer network in swollen state is suitable. The reaction rates increase significantly when the volume of swollen polymer phase is high and the swollen polymer shows low-medium density. Reaction rates are higher as the polymer cross-linking degree (DVB\%) diminishes, since swelling capacity is enhanced in polymers with low cross-linking degree. On the other hand, resin acid capacity and the total number of active sites in a resin hold a lower amount of influence on catalyst performance. However, the acid site density in the swollen polymer $\left(\left[\mathrm{H}^{+}\right] / \mathrm{V}_{\mathrm{sp}}\right)$ plays an important role in the catalytic behavior of resins.

By comparing with the scarce literature survey data, it is seen that the use of gel-type resins as catalysts for the esterification of $\mathrm{LA}$ with $\mathrm{BuOH}$ is a very good option from the viewpoint of green chemistry with the purpose of further industrial application. Gel-type resins have are able to work at lower temperature that inorganic solid catalysts, such as zeolites or montmorillonite supported HPA, and provide LA conversion of about $94 \%$ at lower contact time $\left(w \cdot t / n^{0}{ }_{L A}\right)$. Finally, operating with butanol in excess $(\mathrm{LA} / \mathrm{BuOH}$ of $1 / 3)$ and mild temperature $\left(80^{\circ} \mathrm{C}\right)$ Dowex $50 \mathrm{Wx} 2$ is expected to be stable enough for lengthy industrial operation. 
484 The financial help of the Spanish Ministry of Science and Innovation (project CTQ 2014-56618-R) is

485 kindly acknowledged. We thank Rohm and Haas France and Purolite for supplying Amberlyst and CT

486 ion-exchangers, respectively. Finally, we also thank Dr. Karel Jerabek of Institute of Chemical process

487 Fundamentals (Prague, Czech Republic) for the morphological analyses made by the ISEC method, and

488 Dr. Robert Brown of the School of Applied Sciences and Centre for Applied Catalysis (University of

489 Huddersfield) for helping in acid strength measurements by ammonia adsorption calorimetry.

490

$491 \quad$ Nomenclature

492

BL butyl levulinate

493

$\mathrm{BuOH}$

1-butanol

$494 \quad$ DBE

dibutyl ether

495

$\mathrm{d}_{\text {bead }}$

mean bead diameter (mm)

496

$\mathrm{d}_{\text {pore }}$

mean macropore diameter $(\mathrm{nm})$

497

DVB

divinylbenzene

498

EL

ethyl levulinate

$499 \quad \mathrm{EOE}$

ethyl octyl ether

$500 \quad$ FGB

first generation biofuel

$501 \quad$ HPA

heteropolyacid

502 ISEC

inverse steric exclusion chromatography

503 LA

levulinic acid

$504 \mathrm{n}_{\mathrm{BL}}$

mole of butyl levulinate (mol)

505 PS-DVB polystyrene-divinylbenzene

$506 \mathrm{R}_{\mathrm{BuOH} / \mathrm{LA}}$ molar ratio $\mathrm{BuOH} / \mathrm{LA}$ 
$508 \quad$ SGB $\quad$ second generation biofuel

$509 \quad \mathrm{~S}_{\mathrm{BuOH}}^{\mathrm{BL}} \quad$ selectivity to butyl levulinate

$510 \quad \mathrm{~S}_{\text {pore }} \quad$ surface area $\left(\mathrm{m}^{2} / \mathrm{g}\right)$

$511 \mathrm{t} \quad$ time $(\mathrm{h})$

$512 \quad \mathrm{~T}_{\max } \quad$ maximum working temperature $\left({ }^{\circ} \mathrm{C}\right)$

513 TOF turnover frequency $\left(\mathrm{mol} /\left(\mathrm{h} \cdot \mathrm{eq} \mathrm{H}^{+}\right)\right)$

$514 \quad \mathrm{~V}_{\text {pore }} \quad$ pore volume $\left(\mathrm{cm}^{3} / \mathrm{g}\right)$

$515 \mathrm{~V}_{\mathrm{sp}} \quad$ specific volume of swollen polymer $\left(\mathrm{cm}^{3} / \mathrm{g}\right)$

516 w catalyst mass (g)

$517 \quad \mathrm{X}_{\mathrm{LA}} \quad$ levulinic acid conversion

$518 \quad \rho_{\mathrm{s}} \quad$ skeletal density $\left(\mathrm{g} /\left(\mathrm{cm}^{3}\right.\right.$ of dry catalyst $\left.)\right)$

\section{References}

520 [1] M.J. Climent, A. Corma, S. Iborra, Green Chem. 16(2) (2014) 516-547.

521 [2] S. Banerjee, S. Mudliar, R. Sen, B. Giri, D. Satpute, T. Chakrabarti, R. Pandey, Biofuels, Bioprod. 522 Biorefin. 4(1) (2009) 77-93.

523 [3] N.M. Bennett, S.S. Helle, S.J.B. Duff, Bioresource Technology 100 (2009) 6059-6063

524 [4] S. Zhou, N.B. Osman, H. Li, A.G. McDonald, D. Mourant, C.Z. Li, M. García-Pérez, Fuel 103

$525 \quad$ (2013) 512-523

526 [5] S. Zhou, D. Mourant, C. Lievens, Y. Wang, C. Li, M. García-Pérez, Fuel 104 (2013) 536-546

527 [6] D.J. Hayes, S. Fitzpatrick, M.H.B. Hayes, J.R.H. Ross, in: B. Kamm, P.R. Gruber, M. Kamm, (Eds.)

528 Processes and Products: Status Quo and Future Directions, Wiley-VCH, Weinheim (Germany) 2006.

529 [7] J.J. Bozell, L. Moens, D.C. Elliott, Y. Wang, G.G. Neuenscwander, S.W. Fitzpatrick, R.J. Bilski, J.L. 530 Jarnefeld, 28(3-4) (2000) 227-239.

531 [8] A. Demirbas, Appl. Energy. 88(1) (2011) 17-28. 
532 [9] Grand View Research (2014). http://www.grandviewresearch.com/industry-analysis/levulinic-acid533 market $(05 / 2015)$.

534 [10] L. Lomba, B. Giner, I. Bandrés, C. Lafuente, M.R. Pino, Green Chem. 13(8) (2011) 2062-2070.

535 [11] H.H. Heineman, C.L. Howard, H.J. Rogers, US Patent U.S. Patent 3107224 (1963).

536 [12] A.R. Bader, U.S. Patent 2933520 (1960).

537 [13] F.X. Govers, U.S. Patent 2087473 (1937).

538 [14] D.J. Yontz, U.S. Patent 2011/0274643 A1 (2011).

539 [15] P.D. Bloom, U.S. Patent 2010/0216915 A1 (2010).

540 [16] L.R. Rieth, C.M. Leibig, J.D. Pratt, M. Jackson, M., U.S. Patent 2012/0041110 A1 (2012).

541 [17] P.P.T. Sah, S. Ma, J. Am. Chem. Soc. 52(12) (1930) 4880-4883.

542 [18] H.A. Schuette, M.A. Cowley, J. Am. Chem. Soc. 53(9) (1931) 3485-3489.

543 [19] G.J. Cox, M.L. Dodds, J. Am. Chem. Soc. 55(8) (1933) 3391-3394.

544 [20] G. Pasquale, P. Vázquez, G. Romanelli, G. Baronetti, Catal. Commun. 18 (2012) 115-120.

545 [21] D.R. Fernandes, A.S. Rocha, E.F. Mai, C.J.A. Mota, V. Teixeira Da Silva, Appl. Catal. A Gen. 425$546426(2012) 199-204$.

547 [22] K.Y. Nandiwale, S.K. Sonar, P.S. Niphadkar, P.N. Joshi, S.S. Deshpande, V.S. Patil, V.V. Bokade, 548 Appl. Catal. A Gen. 460-461 (2013) 90-98.

549 [23] K. Yan, G. Wu, J. Wen, A. Chen, Catal. Commun. 34 (2013) 58-63.

550 [24] C.R. Patil, P.S. Niphadkar, V.V. Bokade, P.N. Joshi, Catal. Commun. 43 (2014) 188-191.

551 [25] F. Su, L. Ma, D. Song, X. Zhang, Y. Guo, Green Chem. 15(4) (2013) 885-890.

552 [26] G.D. Yadav, A.R. Yadav, Chem. Eng. J. 243 (2014) 556-563.

553 [27] F. Su, Q. Wu, D. Song, X. Zhang, M. Wang, Y. Guo, J. Mater. Chem. A. 1(42) (2013) 13209-13221.

554 [28] B.L. Oliveira, V. Teixeira Da Silva, Catal. Today. 234 (2014) 257-263.

555 [29] V.L. Budarin, J.H. Clark, R. Luque, D.J. Macquarrie, Chem. Commun. (Camb) 1(6) (2007) 634-636.

556 [30] J.A. Melero, G. Morales, J. Iglesias, M. Paniagua, B. Hernández, S. Penedo, Appl. Catal. A Gen. $557466(2013) 116-122$.

558 [31] Y. Kuwahara, W. Kaburagi, K. Nemoto, T. Fujitani, Appl. Catal. A Gen. 476 (2014) 186-196. 
561 [33] C. Chang, G. Xu, X. Jiang, Bioresour. Technol. 121 (2012) 93-99.

562 [34] P.J. Fagan, E. Korovessi, L. Ernest, R.H. Mehta, S.M. Thomas, U.S. Patent 2003/0233011 A1 563 (2003).

564 [35] R. Liu, J. Chen, X. Huang, L. Chen, L. Ma, X., Li, Green Chem. 15(10) (2013) 2895-2903.

565 [36] L. Peng, L. Lin, J. Zhang, J. Shi, S. Liu, Appl. Catal. A Gen. 397(1-2) (2011) 259-265.

566 [37] E. Christensen, J. Yanowitz, M. Ratcliff, R.L. McCormick, Energy Fuels. 25(10) (2011) 4723-4733.

567 [38] H. Joshi, B.R. Moser, J. Toler, W.F. Smith, T. Walker, Biomass Bioenergy. 35(7) (2011) 3262-3266.

568 [39] E. Christensen, A. Williams, S. Paul, S. Burton, R.L. McCormick, Energy Fuels. 25(11) (2011)

569 $5422-5428$.

570

[40] H.J. Bart, J. Reidetschmger, K. Schatka, A. Lehmann, Ind. Eng. Chem. Res. 33(1) (1994) 21-25.

571

[41] Y. Hishikawa, M. Yamaguchi, S. Kubo, Y. Yamada, J. Wood Sci. 59(2) (2013) 179-182.

572

[42] K.C. Maheria, J. Kozinsji, A. Dalai, Catal. Letters. 143(11) (2013) 1220-1225.

573

[43] K.Y. Nandiwale, V.V. Bokade, Chem. Eng. Technol. 38 (2015) 246-252

574

[44] F.G. Cirujano, A. Corma, F.X. Llabrés, Chem. Eng. Science 124 (2015) 52-60

575

[45] S. Dharme, V.V. Bokade, J. Nat. Gas Chem. 20(1) (2011) 18-24.

576

[46] G.D. Yadav, I.V. Borkar, Ind. Eng. Chem. Res. 47(10) (2008) 3358-3363.

577

[47] A. Guyot, in: D.C. Sherrington, P. Hodge (Eds.), Syntheses and Separations Using Polymers

578 Supports, Wiley, Chichester, 1988, chapter 1

579 [48] P.F. Siril, H.E. Cross, D.R. Brown, J. Mol. Catal. A: Chem. 279 (2008) 63-68.

580 [49] K. Jerabek, L., Hantova, Z. Prokop, 12th International Congress on Catalysis, Granada (Spain), 5812000.

582 [50] K. D. Topp, Room \& Haas, Dow Chemical, personal communication, 2011.

583 [51] R. Bringué, E. Ramírez, M. Iborra, J. Tejero, F. Cunill, J. Catal. 304 (2013) 7-21.

584 [52] S. Fisher, R. Kunnin, Anal. Chem. 27 (1955) 1191-1194.

585 [53] M.A. Pérez-Maciá, R. Bringué, M. Iborra, J. Tejero, F. Cunill, AIChE J. 62 (2016) 180-194

586 [54] R.Bringué, E. Ramírez, M. Iborra, J. Tejero, F. Cunill, Chem. Eng. J. 246 (2014) 71-78 
[55] M.T. Sanz, R. Murga, S. Beltran, J.L. Cabezas, J. Coca, Ind. Eng. Chem. Res. 41 (2002) 512-17

588 [56] S.Y. Chin, M.A.A.Ahmed, M.R. Kamaruzaman, C.K. Cheng, Chem. Eng. Sci. 129 (2015) 116-125

589 [57] C. Casas, R. Bringué, E. Ramírez, M. Iborra, J. Tejero, Appl. Catal. A: Gen. 396 (2011) 129-139.

590 [58] M.J. Lee, J.Y. Chiu, H.M. Lin, Ind. Eng. Chem. Res. 41 (2002) 2882-2887

591 [59] A.M. Ostaniewicz-Cydzik, C.S.M. Pereira, E. Molga, A.E. Rodrigues, Ind. Eng. Chem. Res. 53

$592 \quad$ (2014) 6647-54

593 [60] W.T. Liu, C.S. Tan, Ind. Eng. Chem. Res. 40 (2001) 3281-3286

594 [61] M.J. Lee, H.T. Wu, H.M. Lin, Ind. Eng. Chem. Res. 39 (2000) 4094-4099

595 [62] A. Orjuela, A.J. Yanez, A. Santhanakrishan, C.T. Lira, D.J. Miller, Chem. Eng, J. 188 (2012) 98-

$596 \quad 107$

597 [63] K. Jerabek, ACS Symp. Ser. 635 (1996) 211

598 [64] Ogston, A. G., Trans. Faraday Soc. 54 (1958) 1754-1757.

599 [65] J. Tejero, F. Cunill, M. Iborra, J.F. Izquierdo, C. Fité, J. Mol. Catal. A: Chem. 182-183 (2002) 541600554.

601 [66] K. Jerabek, Anal. Chem. 57 (1985) 1598-1602.

602 [67] A. Biffis, B. Corain, M. Zecca, C. Corvaja, K. Jerabek, J. Am. Chem. Soc. 117 (1995) 1603-1606.

603 [68] M. Hart, G. Fuller, D.R. Brown J.A. Dale, S. Plant, J. Mol. Catal. A. Gen.182-183 (2002) 439

604 [69] N. Bothe, F. Döscher, J. Klein, H. Widdecke, Polymer 20 (1979) 850-854

605 [70] F.T. Fang, in: Proceedings of the Third International Congress on Catalysis, Amsterdam, The 606 Netherlands, vol. 2, 1964, p. 90.

607 [71] L. Petrus, E.J. Stamhuis, G.E.H. Joosten, Ind. Eng. Chem. Prod. Res. Dev. 20 (1981) 366-371

608 [72] J. Guilera, E. Ramírez, C. Fité, M. Iborra, J. Tejero, Appl. Catal. A: General 467 (2013) 301-309

609 [73] I. Dosuna-Rodríguez, E.M. Gaigneaux, Catal. Today 195 (2012) 14-21

610 [74] X. Liao, Y. Zhu, S.G. wang, Y. Li, Fuel Proc. Technol. 90 (2009) 988-993

611 [75] N. Boz, N. Degirmenbasi, D.M, Kalyon, Appl. Catal. B: Environmental 165 (2015) 723-730

612 [76] T. Dong, J. Wang, C. Miao, Y. Zheng, S. Chen, Bioresource Technology 136 (2013) 8-15

613 [77] G.D. Yadav, M.S.M. Mujeebur Rahuman, Org. Proc. Res. Dev. 6 (2002) 706-713

614 [78] S. Karakus, E. Sert, A.D. Buluklu, F.S. Atalay, Ind. Eng. Chem. Res.53 (2014) 4192-4198 
615 [79] S. Kale, S.B. Umbarkar, M.K. Dongare, R. Eckelt, U. Armbruster, A. Martin, Appl. Catal. A:

616 General $490(2015) 10-16$

617 
619 Scheme 1. Acid catalyzed reaction of esterification of levulinic acid

620

621

Figure Captions.

622 Fig. 1. Distribution of zones of different density of swollen PS-DVB catalysts determined from ISEC

623 data in aqueous solution $\left(\square 1.5 \mathrm{~nm} / \mathrm{nm}^{3}, \square 0.8 \mathrm{~nm} / \mathrm{nm}^{3}, \varpi 0.4 \mathrm{~nm} / \mathrm{nm}^{3}, \varpi 0.2 \mathrm{~nm} / \mathrm{nm}^{3}, \varpi 0.1 \mathrm{~nm} / \mathrm{nm}^{3}\right)$

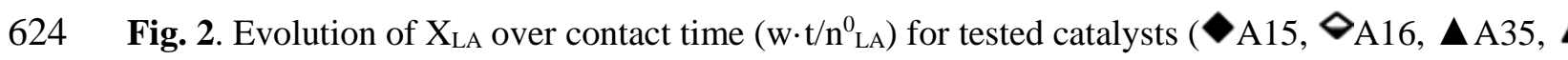

A36, $\square \mathrm{A} 46, \mathbf{A} 70, \diamond \mathrm{A} 39, \Delta \mathrm{CT} 224$, ODOW8, ○DOW 4, •DOW 2)

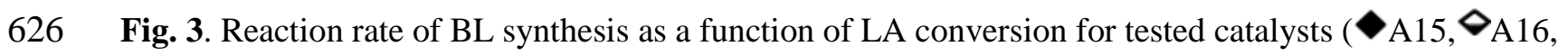

$\boldsymbol{\Delta} \mathrm{A} 35, \boldsymbol{\Delta} \mathrm{A} 36, \square \mathrm{A} 46, \boldsymbol{\nabla} \mathrm{A} 70, \diamond \mathrm{A} 39, \Delta \mathrm{CT} 224$, ODOW8, ○DOW 4, •DOW 2).

628

Fig. 4. TOF of BL synthesis as a function of LA conversion for tested catalysts (

$\mathrm{A} 15, \diamond_{\mathrm{A} 16}$

$\mathrm{A} 35$,

$\Delta \mathrm{A} 36, \square \mathrm{A} 46, \boldsymbol{\square} 70, \diamond \mathrm{A} 39, \Delta \mathrm{CT} 224$, ODOW8, ○DOW 4, •DOW 2).

630

Fig. 5. Influence of chemical and morphological properties in swollen state on resin activity. LA

631 conversion at $2(\diamond), 4(\diamond)$ and $8 \mathrm{~h}(\diamond)$ against macropore volume $(\mathrm{A})$, surface area (B), mean diameter

632 (C), acid capacity (D), crosslinking degree (E) and specific volume of swollen polymer (F)

633

Fig. 6. Relationship between LA conversion and specific volume and density of swollen resins. Right axis: $\mathrm{V}_{\mathrm{sp}}\left(\mathrm{cm}^{3} / \mathrm{g}\right)$ and distribution of zones of different density of swollen PS-DVB resins in water determined from ISEC data in aqueous solution $\left(\backsim 1.5 \mathrm{~nm} / \mathrm{nm}^{3}, \square 0.8 \mathrm{~nm} / \mathrm{nm}^{3}, \varpi 0.4 \mathrm{~nm} / \mathrm{nm}^{3}, \varpi 0.2\right.$ $\left.\mathrm{nm} / \mathrm{nm}^{3}, \bowtie 0.1 \mathrm{~nm} / \mathrm{nm}^{3}\right)$. Left axis: LA conversion achieved at $2(\diamond), 4(\diamond)$ and $8 \mathrm{~h}(\diamond)$ reaction time, 
640 Table 1. Properties of tested catalysts.

\begin{tabular}{|c|c|c|c|c|c|c|}
\hline Catalyst & Acronym & Structure $^{\mathrm{a}}$ & DVB \% ${ }^{b}$ & Sulfonation ${ }^{\mathrm{c}}$ & Acid capacity $\left(\mathrm{meq} \mathrm{H}^{+} / \mathrm{g}\right)^{\mathrm{d}}$ & $\mathbf{T}_{\max }\left({ }^{\circ} \mathbf{C}\right)^{\mathbf{e}}$ \\
\hline Amberlyst 15 & A15 & macro & 20 & CS & 4.81 & 120 \\
\hline Amberlyst 16 & A16 & macro & 12 & $\mathrm{CS}$ & 4.80 & 130 \\
\hline Amberlyst 35 & A35 & macro & 20 & OS & 5.32 & 150 \\
\hline Amberlyst 36 & A36 & macro & 12 & OS & 5.40 & 150 \\
\hline Amberlyst 39 & A39 & macro & 8 & $\mathrm{CS}$ & 4.82 & 130 \\
\hline Amberlyst 46 & A46 & macro & 25 & SS & 0.87 & 120 \\
\hline Amberlyst 70 & A70 & macro & 8 & $\mathrm{CS}$ & 2.55 & 190 \\
\hline Purolite CT224 & CT224 & gel & 4 & OS & 5.34 & 150 \\
\hline Dowex 50Wx2 & DOW2 & gel & 2 & $\mathrm{CS}$ & 4.83 & 150 \\
\hline Dowex $50 \mathrm{Wx} 4$ & DOW4 & gel & 4 & CS & 4.95 & 150 \\
\hline Dowex 50Wx8 & DOW8 & gel & 8 & $\mathrm{CS}$ & 4.83 & 150 \\
\hline
\end{tabular}
(a) Macroreticular structure (macro) and gel-type structure (gel).
(b) From Bringué et al. [51].
(c) Conventionally sulfonated (CS), oversulfonated (OS) and surface sulfonated (SS).
(d) Titration against standard base following the procedure described by Fisher and Kunin [52].
(e) Maximum operation temperature. Information supplied by manufacturer

641

642

643

644 Table 2. Morphology of tested catalysts swollen in water.

\begin{tabular}{|c|c|c|c|c|c|c|c|c|c|c|}
\hline \multirow{3}{*}{ Catalyst } & \multirow{3}{*}{$\begin{array}{l}\rho_{\mathrm{s}}{ }^{\mathrm{a}} \\
\left(\mathrm{g} / \mathrm{cm}^{3}\right)\end{array}$} & \multicolumn{3}{|c|}{ True pores $^{\mathrm{b}}$} & \multicolumn{6}{|c|}{ Gel-phase $^{\text {b }}$} \\
\hline & & \multirow{2}{*}{$\begin{array}{l}\mathbf{d}_{\text {pore }}{ }^{\mathrm{c}} \\
(\mathbf{n m})\end{array}$} & \multirow{2}{*}{$\begin{array}{l}\Sigma S_{\text {pore }} \\
\left(\mathrm{m}^{2} / \mathbf{g}\right)\end{array}$} & \multirow{2}{*}{$\begin{array}{c}\Sigma V_{\text {pore }} \\
\left(\mathrm{cm}^{3} / \mathbf{g}\right)\end{array}$} & \multirow{2}{*}{$\begin{array}{c}\Sigma V_{\text {sp }} \\
\left(\mathrm{cm}^{3} / \mathrm{g}\right)\end{array}$} & \multicolumn{5}{|c|}{$\mathbf{V}_{\mathrm{sp}}\left(\mathrm{cm}^{3} / \mathbf{g}\right)$} \\
\hline & & & & & & $0.1 \mathrm{~nm} / \mathrm{nm}^{3}$ & $0.2 \mathrm{~nm} / \mathrm{nm}^{3}$ & $0.4 \mathrm{~nm} / \mathbf{n m}^{3}$ & $0.8 \mathrm{~nm} / \mathrm{nm}^{3}$ & $1.5 \mathrm{~nm} / \mathrm{nm}^{3}$ \\
\hline A15 & 1.416 & 12.4 & 192 & 0.616 & 0.622 & 0.000 & 0.000 & 0.000 & 0.000 & 0.622 \\
\hline A16 & 1.401 & 15.5 & 46 & 0.188 & 1.136 & 0.208 & 0.000 & 0.000 & 0.016 & 0.913 \\
\hline A35 & 1.542 & 12.6 & 199 & 0.720 & 0.504 & 0.000 & 0.000 & 0.005 & 0.065 & 0.434 \\
\hline A36 & 1.567 & 14.8 & 68 & 0.259 & 1.261 & 0.000 & 0.085 & 0.015 & 0.000 & 1.161 \\
\hline A39 & 1.417 & 15.0 & 56 & 0.155 & 1.643 & 0.218 & 0.000 & 0.588 & 0.243 & 0.595 \\
\hline A46 & 1.137 & 10.3 & 186 & 0.470 & 0.190 & 0.010 & 0.000 & 0.000 & 0.016 & 0.164 \\
\hline $\mathrm{A} 70$ & 1.520 & 13.2 & 66 & 0.220 & 1.149 & 0.071 & 0.007 & 1.072 & 0.000 & 0.000 \\
\hline CT224 & 1.424 & - & - & - & 1.859 & 0.000 & 0.000 & 0.511 & 0.765 & 0.584 \\
\hline DOW2 & 1.426 & - & - & - & 2.677 & 0.000 & 0.729 & 1.949 & 0.000 & 0.000 \\
\hline DOW4 & 1.426 & - & - & - & 1.920 & 0.000 & 0.000 & 1.356 & 0.953 & 0.000 \\
\hline DOW8 & 1.430 & - & - & - & 1.404 & 0.000 & 0.034 & 0.000 & 0.046 & 1.325 \\
\hline
\end{tabular}
(a) Skeletal density measured by Helium displacement (dry state).
(b) Determined from ISEC data.
(c) Mean pore diameter. 
Table 3. Conversion values at 2,4 and $8 \mathrm{~h}$ reaction time and the final selectivity values.

\begin{tabular}{|c|c|c|c|c|}
\hline \multirow{2}{*}{ Catalyst } & \multicolumn{3}{|c|}{$\mathrm{X}_{\mathrm{LA}}(\%)$} & \multirow{2}{*}{$\mathbf{S}_{\mathrm{BuOH}}^{\mathrm{BL}}(\mathbf{8 h}, \%)$} \\
\hline & $t=2 h$ & $t=4 h$ & $t=8 h$ & \\
\hline Amberlyst 46 & --- & 45.7 & 63.9 & 99.6 \\
\hline Amberlyst 15 & 39.3 & 52.7 & 69.8 & 99.7 \\
\hline Amberlyst 35 & 40.5 & 55.0 & 70.9 & 99.8 \\
\hline Amberlyst 16 & 41.2 & 55.7 & 74.9 & 99.6 \\
\hline Amberlyst 36 & 46.7 & 59.7 & 78.1 & 99.5 \\
\hline Amberlyst 39 & 54.9 & 72.2 & 86.6 & 99.9 \\
\hline Amberlyst 70 & 46.8 & 62.8 & 81.0 & 99.9 \\
\hline Dowex $50 \mathrm{Xx} 8$ & 48.2 & 63.3 & 81.3 & 99.7 \\
\hline CT-224 & 61.0 & 77.4 & 90.6 & 99.8 \\
\hline Dowex $50 \mathrm{Xx} 4$ & 66.8 & 82.5 & 92.4 & 99.9 \\
\hline Dowex $50 X x 2$ & 71.8 & 86.3 & 93.6 & 99.9 \\
\hline
\end{tabular}

649

650

651

652

Table 4. $\mathrm{NH}_{3}$ adsorption enthalpy and acid capacity from $\mathrm{NH}_{3}$ adsorption calorimetry.

\begin{tabular}{lcccl}
\hline Catalyst & $-\Delta \mathbf{H}_{\mathbf{N H 3}}(\mathbf{k J} / \mathbf{m o l})$ & {$\left[\mathbf{H}^{+}\right](\mathbf{m m o l} / \mathbf{g})^{\mathbf{a}}$} & {$\left[\mathbf{H}^{+}\right](\mathbf{m m o l} / \mathbf{g})^{\mathbf{b}}$} & \multicolumn{1}{c}{ Ref } \\
\hline Amberlyst 15 & $111 \pm 2$ & $4.70 \pm 0.1$ & 4.81 & 48 \\
& $110 \pm 3$ & $4.73 \pm 0.1$ & & This work \\
Amberlyst 35 & $117 \pm 2$ & $5.20 \pm 0.1$ & 5.32 & 48 \\
Amberlyst 16 & $108 \pm 3$ & 4.72 & 4.80 & This work \\
Amberlyst 36 & $117 \pm 2$ & $5.30 \pm 0.1$ & 5.40 & 48 \\
Amberlyst 39 & $111 \pm 3$ & 4.66 & 4.82 & This work \\
Amberlyst 70 & $117 \pm 3$ & $1.65 \pm 0.05$ & 2.55 & 48 \\
Dowex 50Wx4 & $113 \pm 3$ & 4.65 & 4,95 & This work \\
Dowex 50Wx2 & $106 \pm 3$ & 3.80 & 4.83 & This work \\
Purolite CT224 & $112 \pm 3$ & 4.51 & 5.34 & This work \\
Amberlyst 46 & $108 \pm 3$ & 0.91 & 0.87 & This work \\
\hline
\end{tabular}

The experimental technique can be found in Siril et al. [48]

${ }^{a}$ From microcalorimetry of $\mathrm{NH}_{3}$ adsorption. It considers those centers with $-\Delta \mathrm{H}_{\mathrm{NH} 3} \geq 80 \mathrm{~kJ} / \mathrm{mol}$ ${ }^{\mathrm{b}}$ From titration with $\mathrm{NaOH}$ 
657 Table 5. Summary of experimental conditions used in synthesis of BL by heterogeneous catalysis.

\begin{tabular}{llllllll}
\hline Ref. & Catalyst & Solvent & Catalyst loading & $\mathbf{t}(\mathbf{h})$ & $\mathbf{T}\left({ }^{\mathbf{o}} \mathbf{C}\right)$ & $\mathbf{R}_{\mathbf{L A} / \mathbf{B u O H}}$ & $\mathbf{X}_{\mathbf{L A}}(\boldsymbol{\%})$ \\
\hline & PS-DVB resins & None $(\mathrm{BuOH})$ & $0.8 \%$ & 8 & 80 & $1 / 3$ & $64-94 \%{ }^{(\mathrm{a})}$ \\
\hline 42 & Zeolites & None $(\mathrm{BuOH})$ & $7-14 \mathrm{wt} \%$ & $4-12$ & 120 & $1 / 6-1 / 8$ & $31-82^{(\mathrm{b})}$ \\
43 & Modified H-ZSM-5 & None $(\mathrm{BuOH})$ & $20 \mathrm{wt} . \%$ & 6 & $90-130$ & $1 / 6$ & $95-98^{(\mathrm{c})}$ \\
44 & Zr-containing MOFs & None $(\mathrm{BuOH})$ & & 6 & 120 & $1 / 6$ & $999^{(\mathrm{d})}$ \\
45 & HPA on K10 & None $(\mathrm{BuOH})$ & $7-30 \mathrm{wt} \%$ & $1-6$ & 120 & $1 / 4-1 / 10$ & $60-97^{(\mathrm{e})}$ \\
46 & Immobilized lipase & t-butyl methyl ether & $10-50 \mathrm{mg}$ & 2 & $30-60$ & $1 / 1-1 / 4$ & $35-86^{(\mathrm{f})}$ \\
\hline
\end{tabular}

(a) Best catalyst: Dowex $50 \mathrm{Wx} 2 . \mathrm{X}_{\mathrm{LA}}=94 \% ; \mathrm{w} \cdot \mathrm{t} / \mathrm{n}^{0} \mathrm{LA} \approx 22 \mathrm{~g}$ catalyst $\cdot \mathrm{h} / \mathrm{mol} \mathrm{LA}$

(b) Best catalyst: H-BEA-25 ( $\mathrm{R}_{\mathrm{LA} / \mathrm{BuOH}}=1 / 7$, catalyst loading $10 \mathrm{wt} . \%$ to $\left.\mathrm{LA}\right) . \mathrm{X}_{\mathrm{LA}}=82.2 \%$; $\mathrm{w} \cdot \mathrm{t} / \mathrm{n}^{0}{ }_{\mathrm{LA}} \approx 46 \mathrm{~g}$ catalyst $\cdot \mathrm{h} / \mathrm{mol} \mathrm{LA}$

(c) Best catalyst: micro/meso H-ZSM-5 ( $\mathrm{R}_{\mathrm{LA} / \mathrm{BuOH}}=1 / 6$, catalyst loading $20 \mathrm{wt} . \%$ to $\left.\mathrm{LA}, \mathrm{T}=130^{\circ} \mathrm{C}\right) . \mathrm{X}_{\mathrm{LA}}=98 \%$; $\mathrm{w} \cdot \mathrm{t} / \mathrm{n}^{0} \mathrm{LA} \approx 140 \mathrm{~g}$ catalyst $\cdot \mathrm{h} / \mathrm{mol} \mathrm{LA}$

(d) Best catalyst: Zr-containing $\mathrm{MOF}(1.8 \% \mathrm{Zr})\left(\mathrm{R}_{\mathrm{LA} / \mathrm{BuOH}}=1 / 6\right.$, catalyst loading $\left.1.8 \mathrm{~mol} . \% \mathrm{Zr}\right) . \mathrm{X}_{\mathrm{LA}}=99 \%$

(e) Best catalyst: K10-supported dodecamolibdophosphoric acid $\left(\mathrm{R}_{\mathrm{LA} / \mathrm{BuOH}}=1 / 6\right.$, catalyst loading $10 \mathrm{wt} \%$ to $\left.\mathrm{LA}\right)$. $\mathrm{X}_{\mathrm{LA}}=97 \%$, selectivity to $\mathrm{BL}=100 \% ; \mathrm{w} \cdot \mathrm{t} / \mathrm{n}_{\mathrm{LA}}^{0} \approx 70 \mathrm{~g}$ catalyst $\cdot \mathrm{h} / \mathrm{mol} \mathrm{LA}$

(f) Best catalyst: immobilized Novozim $435\left(\mathrm{R}_{\mathrm{LA} / \mathrm{BuOH}}=1 / 3\right.$, catalyst loading $\left.35 \mathrm{mg}[0.3 \mathrm{wt} . \%], \mathrm{T}=60^{\circ} \mathrm{C}\right) . \mathrm{X}_{\mathrm{LA}}=$ $86 \%$ 
661<smiles>[R]OC(=O)CCC(=O)[C@@H](O)[C@@H]([R20])O</smiles>

662

663 Scheme 1. Acid catalyzed reaction of esterification of levulinic acid

664 


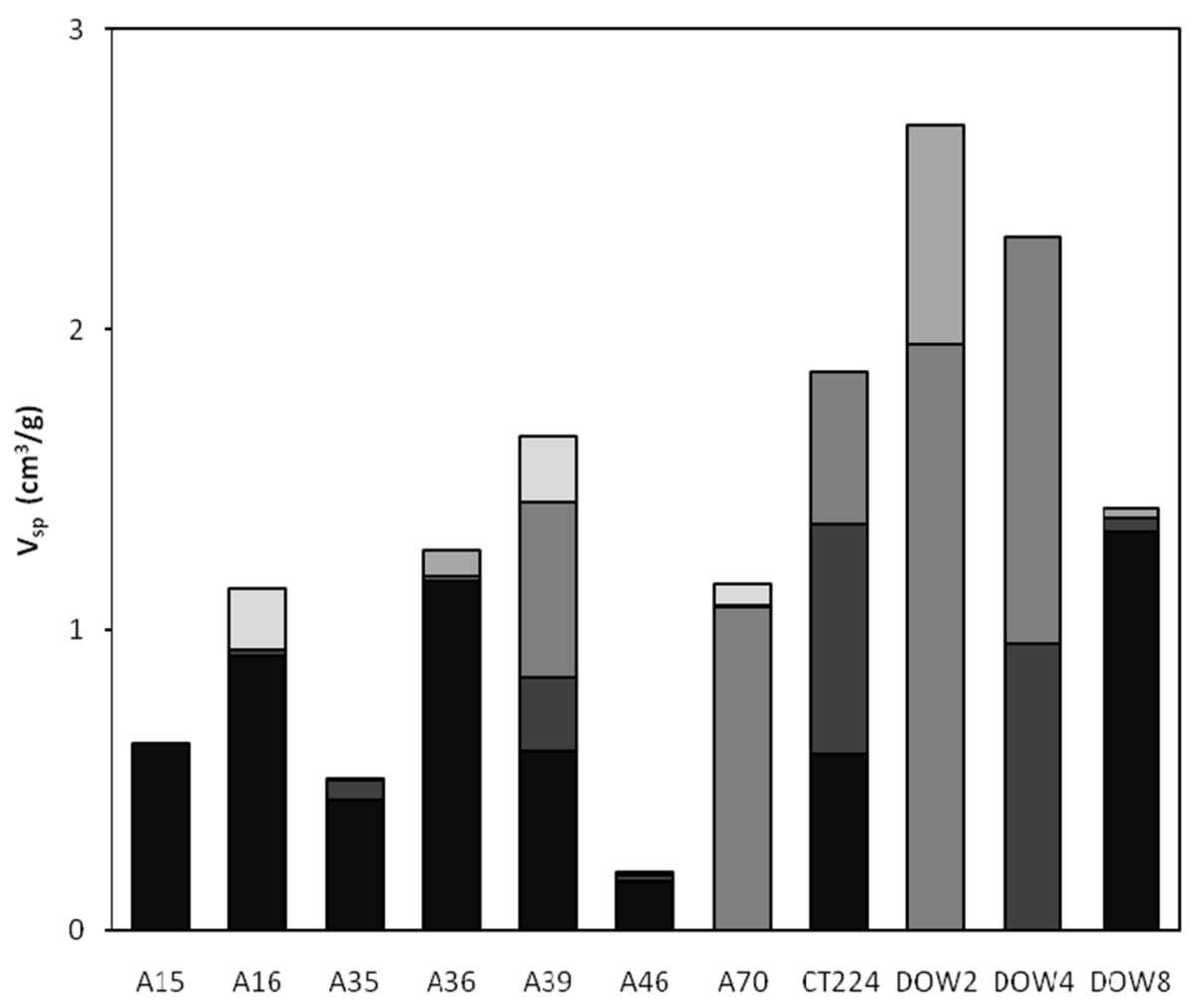

669 Fig. 1. Distribution of zones of different density of swollen PS-DVB catalysts determined from ISEC data in aqueous solution $\left(\square 1.5 \mathrm{~nm} / \mathrm{nm}^{3}, \square 0.8 \mathrm{~nm} / \mathrm{nm}^{3}, \square 0.4 \mathrm{~nm} / \mathrm{nm}^{3}, \square 0.2 \mathrm{~nm} / \mathrm{nm}^{3}, \square 0.1 \mathrm{~nm} / \mathrm{nm}^{3}\right)$ 


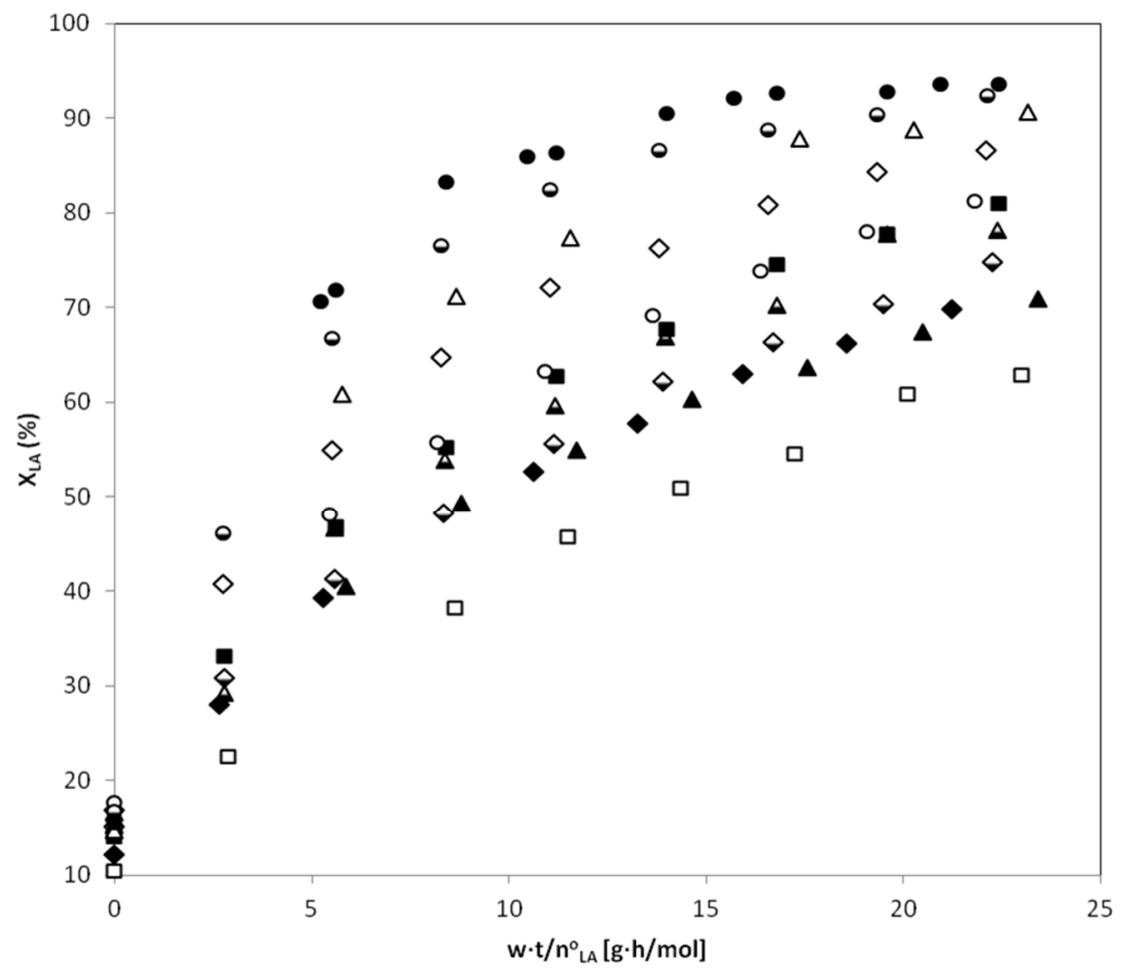

674

675 Fig. 2. Evolution of $\mathrm{X}_{\mathrm{LA}}$ over contact time $\left(\mathrm{w} \cdot \mathrm{t} / \mathrm{n}^{0}{ }_{\mathrm{LA}}\right)$ for tested catalysts $\left(\boldsymbol{A}_{\mathrm{A} 15,} \boldsymbol{\diamond}_{\mathrm{A} 16, \boldsymbol{\Delta} \mathrm{A} 35, \boldsymbol{\Delta}}\right.$ 676 A36, $\square \mathrm{A} 46, \boldsymbol{A} 70, \diamond \mathrm{A} 39, \Delta \mathrm{CT} 224$, ODOW8, ○DOW 4, •DOW 2) 
678

679

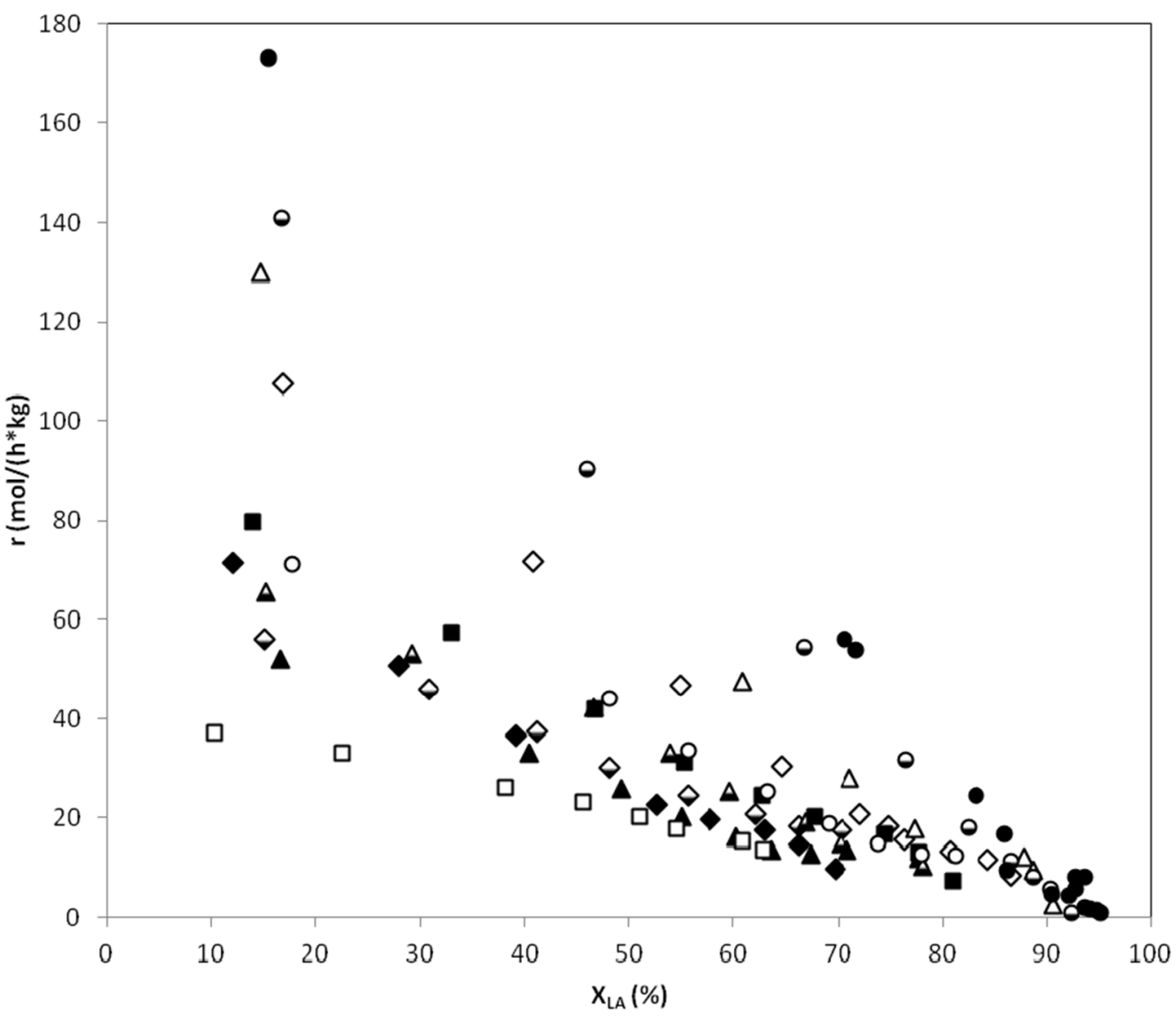

680

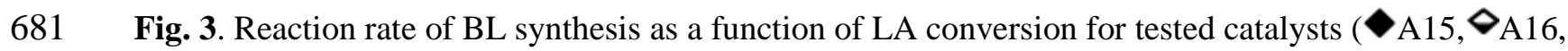
682 $\Delta \mathrm{A} 35, \Delta \mathrm{A} 36, \square \mathrm{A} 46, \mathbf{a} 70, \diamond \mathrm{A} 39, \Delta \mathrm{CT} 224$, ODOW8, ○DOW 4, •DOW 2).

683 
684

685

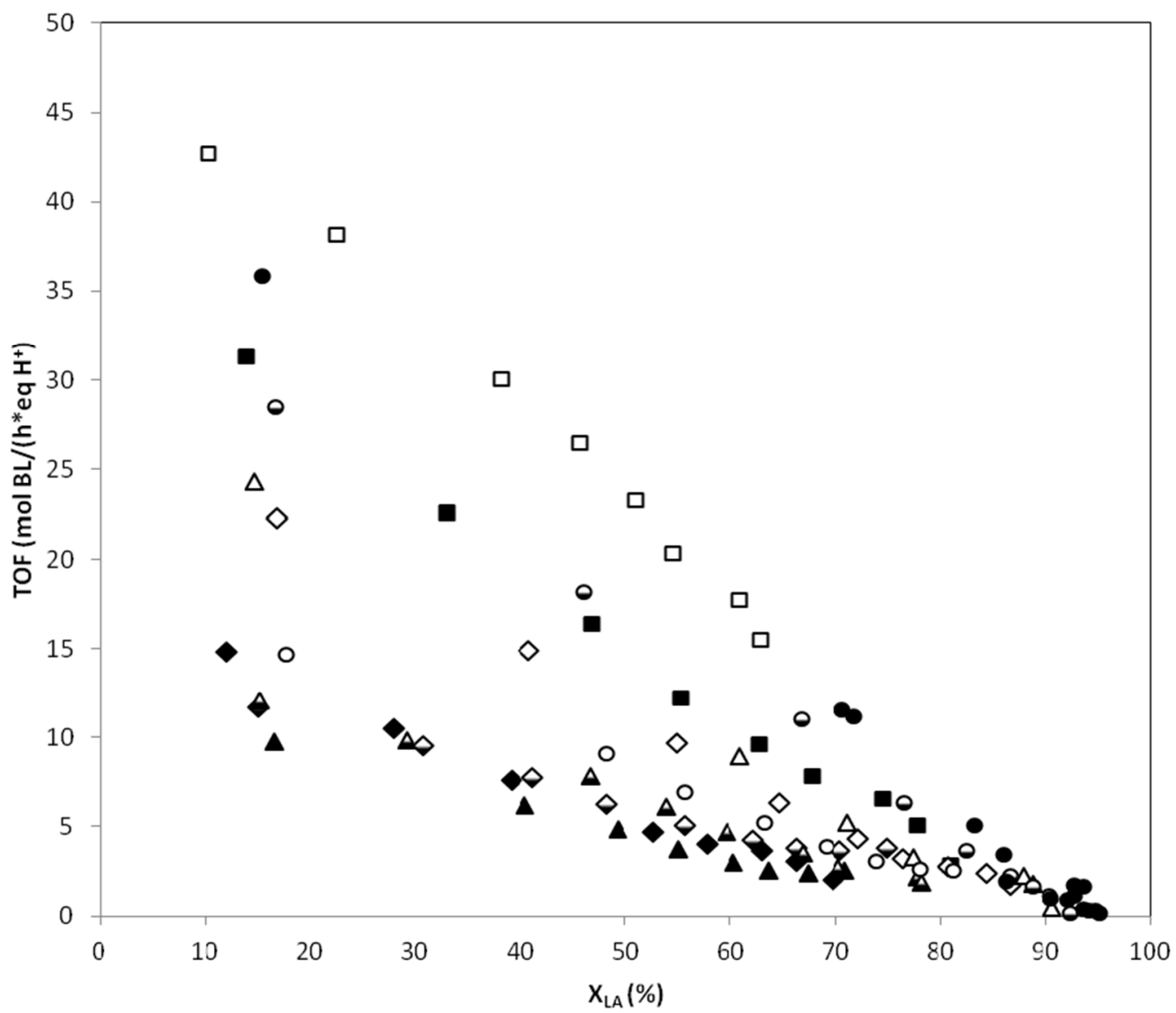

686

687 Fig. 4. TOF of BL synthesis as a function of LA conversion for tested catalysts $\left(\bullet_{A} 15, \diamond_{A} 16, \boldsymbol{\Delta}\right.$ A35, 688

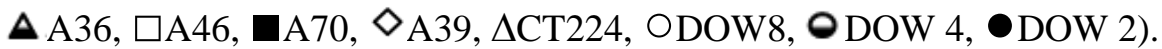



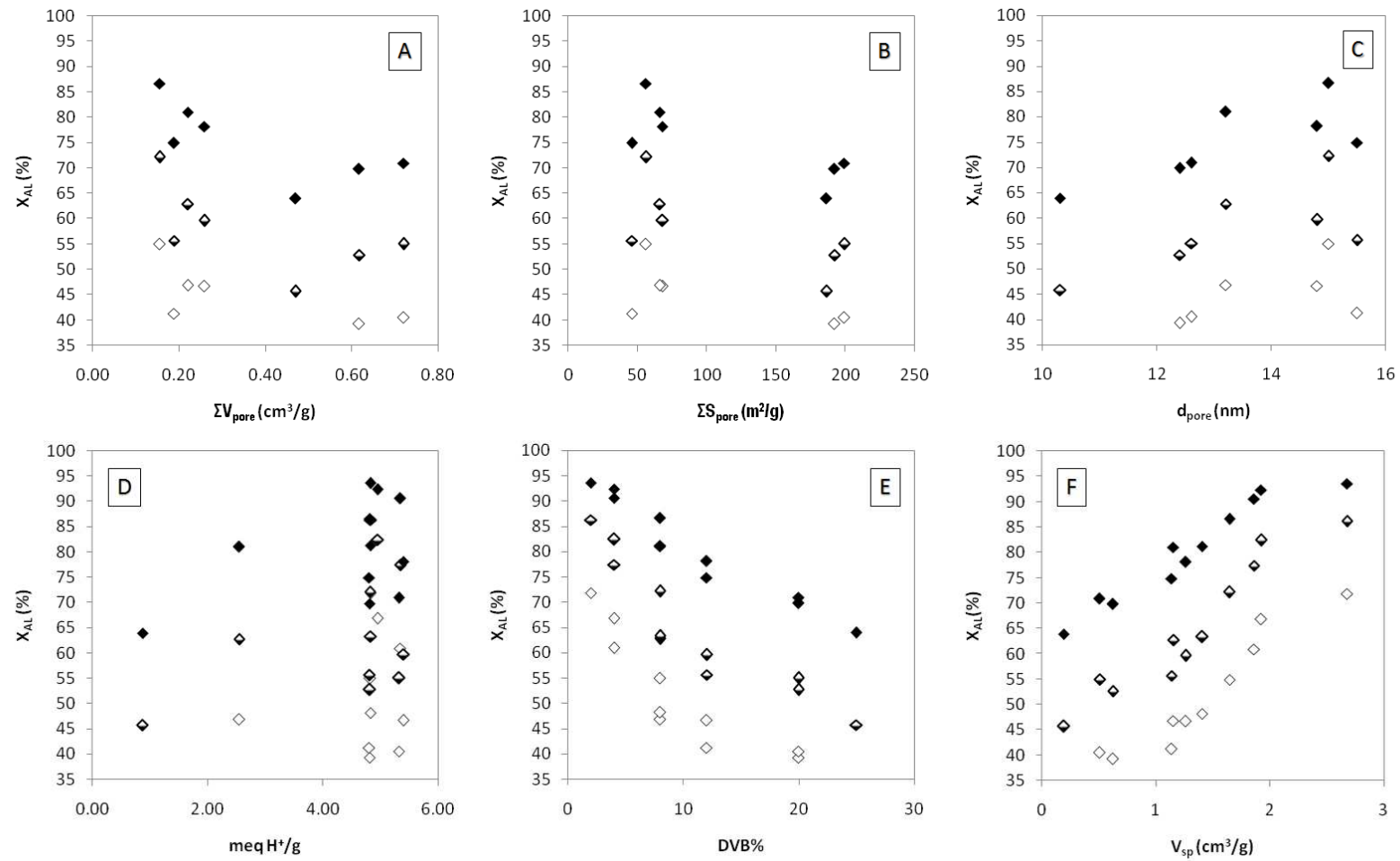

Fig. 5. Influence of chemical and morphological properties in swollen state on resin activity. LA conversion at $2(\diamond), 4(\diamond)$ and $8 \mathrm{~h}(\diamond)$ against macropore volume $(\mathrm{A})$, surface area (B), mean diameter 695 (C), acid capacity (D), crosslinking degree (E) and specific volume of swollen polymer (F)

696 


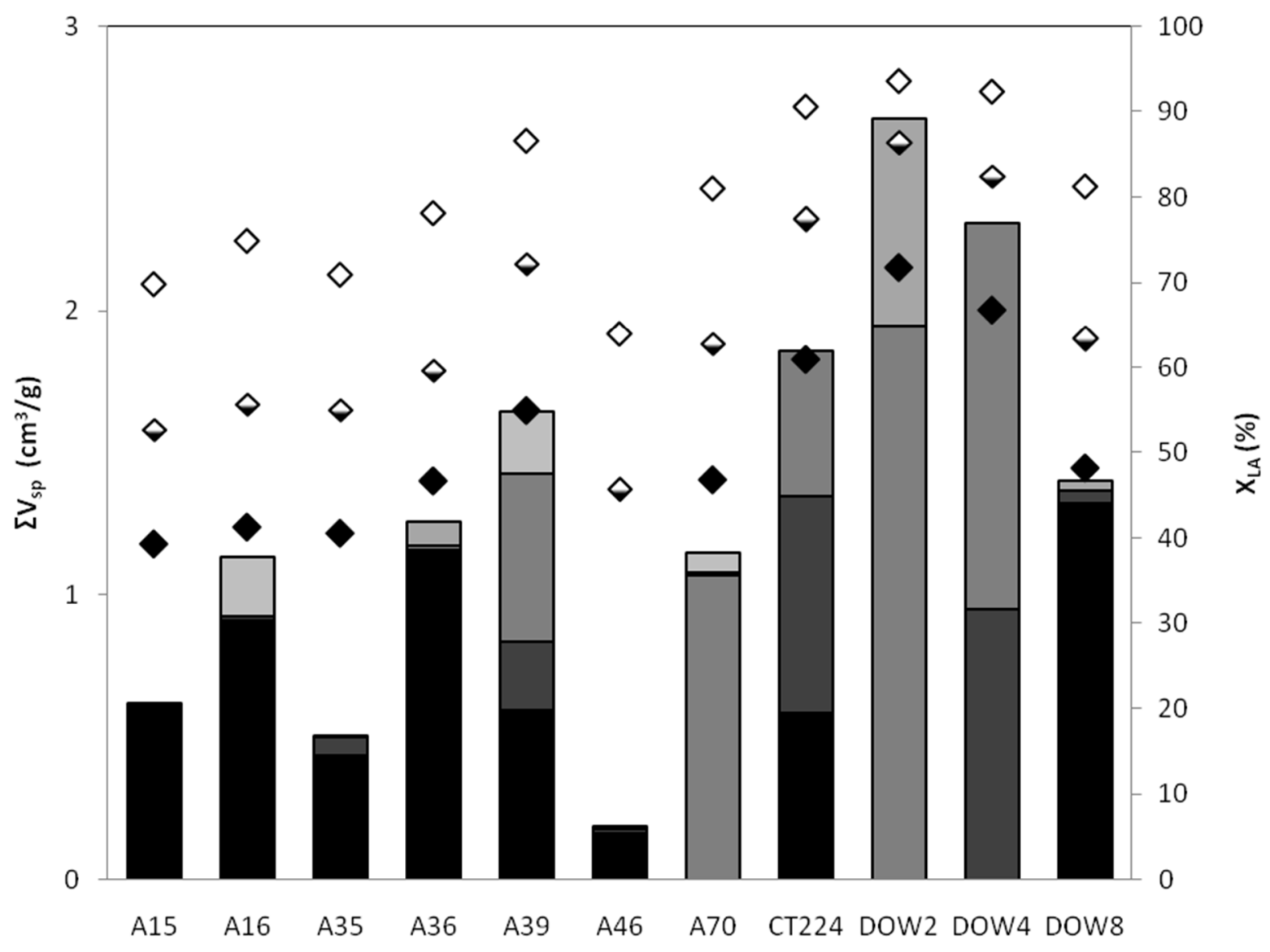

700 Fig. 6. Relationship between LA conversion and specific volume and density of swollen resins. Right axis: $\mathrm{V}_{\mathrm{sp}}\left(\mathrm{cm}^{3} / \mathrm{g}\right)$ and distribution of zones of different density of swollen PS-DVB resins in water determined from ISEC data in aqueous solution $\left(\square 1.5 \mathrm{~nm} / \mathrm{nm}^{3}, \square 0.8 \mathrm{~nm} / \mathrm{nm}^{3}, \square 0.4 \mathrm{~nm} / \mathrm{nm}^{3}\right.$, $\square 0.2$ $\left.\mathrm{nm} / \mathrm{nm}^{3}, \bowtie 0.1 \mathrm{~nm} / \mathrm{nm}^{3}\right)$. Left axis: LA conversion achieved at $2(\diamond), 4(\diamond)$ and $8 \mathrm{~h}(\diamond)$ reaction time, 


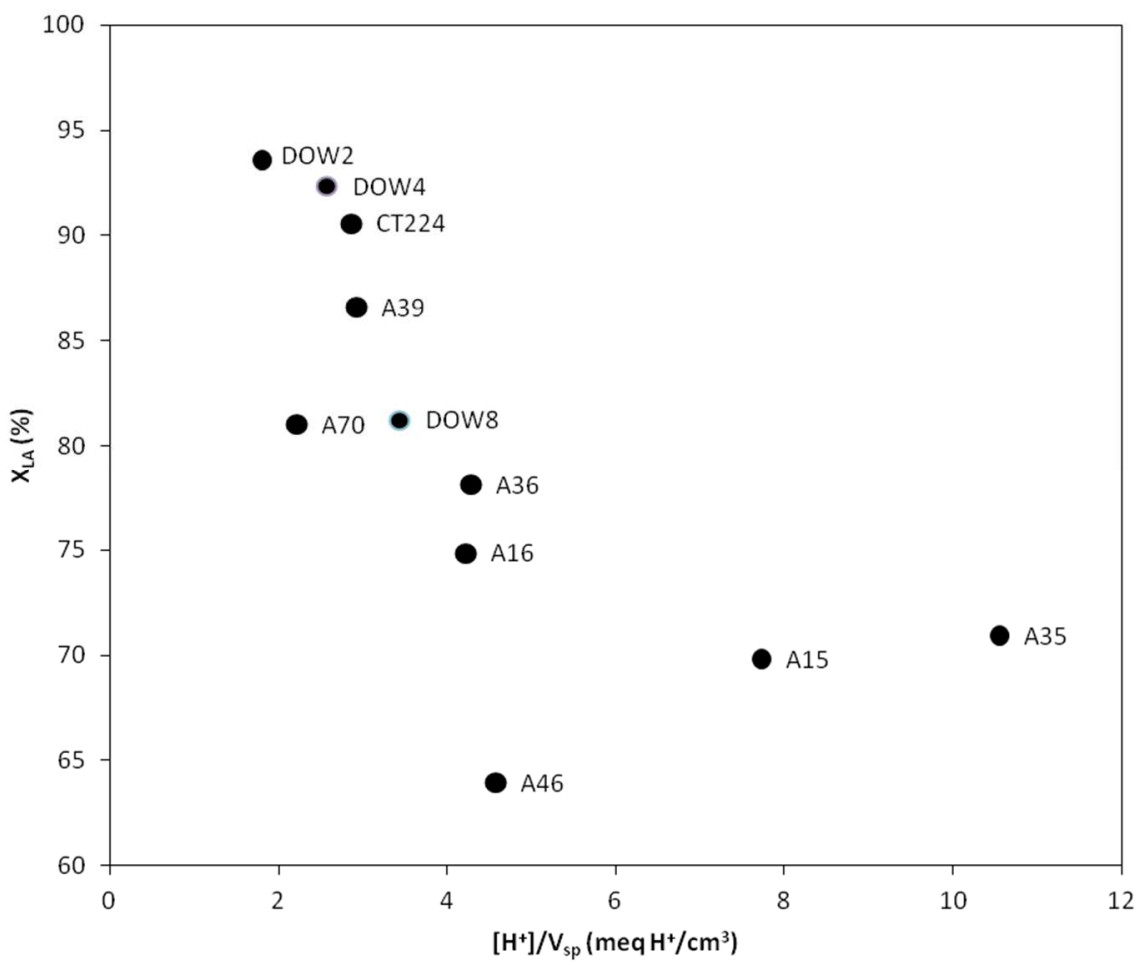

707

Fig. 7. LA conversion at $8 \mathrm{~h}$ reaction time vs. $\left[\mathrm{H}^{+}\right] / \mathrm{V}_{\mathrm{sp}}$ 